\title{
Hydrologic Impacts of Ensemble-RCM-Projected Climate Changes in the Athabasca River Basin, Canada
}

\author{
Xiong Zhou, ${ }^{\mathrm{a}}$ Guohe Huang, ${ }^{\mathrm{a}}$ Joseph Piwowar, ${ }^{\mathrm{b}}$ Yurui Fan, ${ }^{\mathrm{a}}$ Xiuquan Wang, ${ }^{\mathrm{c}}$ Zoe Li, ${ }^{\mathrm{d}}$ \\ AND GUANHUI CHENG ${ }^{\mathrm{a}}$ \\ ${ }^{a}$ Institute for Energy, Environment and Sustainable Communities, University of Regina, Regina, Saskatchewan, Canada \\ ${ }^{\mathrm{b}}$ Department of Geography and Environmental Studies, University of Regina, Regina, Saskatchewan, Canada \\ ${ }^{\mathrm{c}}$ School of Climate Change and Adaptation, University of Prince Edward Island, Charlottetown, Prince Edward Island, Canada \\ ${ }^{\mathrm{d}}$ Department of Civil Engineering, McMaster University, Hamilton, Ontario, Canada
}

(Manuscript received 1 December 2017, in final form 10 September 2018)

\begin{abstract}
In this study, the Providing Regional Climates for Impacts Studies (PRECIS) and the Regional Climate Model (RegCM) system as well as the Variable Infiltration Capacity (VIC) macroscale hydrologic model were integrated into a general framework to investigate impacts of future climates on the hydrologic regime of the Athabasca River basin. Regional climate models (RCMs) including PRECIS and RegCM were used to develop ensemble high-resolution climate projections for 1979-2099. RCMs were driven by the boundary conditions from the Hadley Centre Global Environment Model, version 2 with Earth system configurations (HadGEM2-ES); the Second Generation Canadian Earth System Model (CanESM2); and the Geophysical Fluid Dynamics Laboratory Earth System Model with MOM (GFDL-ESM2M) under the representative concentration pathways (RCPs). The ensemble climate simulations were validated through comparison with observations for 1984-2003. The RCMs project increases in temperature, precipitation, and wind speed under RCPs across most of the Athabasca River basin. Meanwhile, VIC was calibrated using the University of Arizona Shuffled Complex Evolution method (SCE-UA). The performance of the VIC model in replicating the characteristics of the observed streamflow was validated for 1994-2003. Changes in runoff and streamflow under RCPs were then simulated by the validated VIC model. The validation results demonstrate that the ensemble-RCM-driven VIC model can effectively reproduce historical climatological and hydrological patterns in the Athabasca River basin. The ensemble-RCM-driven VIC model shows that monthly streamflow is projected to increase in the 2050s and 2080s under RCPs, with notably higher flows expected in the spring for the 2080s. This will have substantial impacts on water balance on the Athabasca River basin, thus affecting the surrounding industry and ecosystems. The developed framework can be applied to other regions for exploration of hydrologic impacts under climate change.
\end{abstract}

\section{Introduction}

Climate change has significant implications on water resources and freshwater ecosystems (Eum et al. 2017; Özdogan 2011). Regional climate models (RCMs) and macroscale hydrologic models (MHMs) are common approaches to investigate the effects of projected climate changes on local hydrological regimes. RCMs are able to simulate detailed regional atmospheric and terrestrial processes (Denis et al. 2002; Jones et al. 1995), while MHMs have advantages in representing spatial variability of water resources. When linked with RCMs, MHMs can model water resources systems at a fine spatial resolution (Raje and Krishnan 2012).

Corresponding author: Dr. Guohe Huang, huangg@uregina.ca
The Athabasca River is the longest undammed river in the Canadian Prairies, and the potential effects of climate change on its hydrological cycles have been implicated for water scarcities, wild fires, flooding, and droughts (Cheng et al. 2017). Further, annual flows of the Athabasca River have been shown to be linked with historic climate conditions across this region, a trend that is expected to continue into the future (Edwards et al. 2008; Sauchyn et al. 2015; Schindler and Donahue 2006). A better understanding how climate change will affect the spatial and temporal variability of hydrologic regimes in prairie river basins, such as the Athabasca, is needed in order to support proper mitigation and adaptation strategies (IPCC 2013; Maurer et al. 2007).

Previous studies have attempted to investigate the potential effects of climate change on hydrologic regimes 
using MHMs driven by global climate models (GCMs; Cheng et al. 2017; Cherkauer and Sinha 2010; Eum et al. 2017; Nijssen et al. 2001; Rajagopal et al. 2014; Schnorbus and Cannon 2014; Shrestha et al. 2012, 2014a). For example, Nijssen et al. (2001) employed climate predictions from four GCMs to analyze hydrologic sensitivities and impacts in nine large river basins. Cherkauer and Sinha (2010) evaluated potential effects of projected future climate change on the hydrology of the four American states surrounding Lake Michigan through the Variable Infiltration Capacity (VIC) macroscale hydrologic model (Liang et al. 1994), which was driven by statistically downscaled projections from GCMs. Shrestha et al. (2012) used the VIC hydrologic model and statistically downscaled outputs from GCMs to investigate the spatial and temporal variability of climate-induced hydrologic changes in the Fraser River basin, British Columbia, Canada. Shrestha et al. (2014b) applied simulated hydrologic changes by a downscaled GCM-driven VIC model, and then investigated potential hydroclimatic change in the Peace River basin in British Columbia. Schnorbus and Cannon (2014) generated large ensembles of hydrologic projections for two watersheds in British Columbia using the VIC and statistical emulation model. Rajagopal et al. (2014) examined the potential impacts of projected climate change by GCMs on the water balance of the Salt and Verde River basins.

Recently, Eum et al. (2017) investigated the hydrologic response of the Athabasca River basin in Alberta, Canada, to the projected changes statistically downscaled from GCMs using the VIC process-based and distributed hydrologic model. However, statistical downscaling is based on an unverifiable assumption that the statistical relationships between atmospheric variables on large-scale and local variables of interest should be stationary under various climatic conditions (Vincent and Gullett 1999; Wilby et al. 2004; Zhou et al. 2018b). Nevertheless, dynamical downscaling is consistent with physical mechanisms in GCMs to resolve more detailed features within GCM grids such as mountain ranges, coastal zones, and details of soil properties (Feser et al. 2011). However, there have been no attempts to dynamically investigate hydrologic impacts on the basis of ensemble RCM projections over the Athabasca River basin under RCPs, as recommended by the IPCC in 2013 (IPCC 2013; Van Vuuren et al. 2011).

As the study area of this research is very close to the Rocky Mountains, where the local climate will be significantly affected by the various topography, land use/cover, and soil types, it is therefore important to use dynamical downscaling to investigate and quantify how these local features will influence the local climatology, eventually to understand how the affected climatology will impact the local hydrology. This is, in fact, the motivation of our research. Many recent papers suggest that there are clearly added values from dynamical downscaling to GCMs in capturing the local climate variations (Wang et al. 2014, 2015b; Zhou et al. 2018a,b,d). Therefore, in this study, the Regional Climate Model (RegCM) and Providing Regional Climates for Impacts Studies (PRECIS) are employed to generate downscaled climate projections from the Hadley Centre Global Environment Model, version 2 with Earth system configurations (HadGEM2-ES), Second Generation Canadian Earth System Model (CanESM2), and Geophysical Fluid Dynamics Laboratory Earth System Model with MOM (GFDL-ESM2M) in order to investigate the impacts of future climate change on the hydrologic regimes in the Athabasca River basin. Moreover, the VIC model is employed due to its advantages in spatially representing physical processes within RCM grids in the Athabasca River basin.

The objective of this study is to investigate the impacts of future climates on the hydrologic regimes in the Athabasca River basin through the use of an integrated regional climate model and macroscale hydrologic model. Specifically, the PRECIS and RegCM modeling systems (Jones et al. 2004) are first used to develop highresolution regional climate projections over the Athabasca River basin. The performance of the ensemble RCM simulations is then validated through comparison with observed temperature, precipitation, and wind data from the baseline period (1984-2003). Meanwhile, the macroscale VIC hydrologic model is calibrated for the period of 1984-93 in the Athabasca River basin using the University of Arizona Shuffled Complex Evolution method (SCE-UA; Duan et al. 1994). The performance of the VIC model in replicating the characteristics of the observed streamflow in the Athabasca River basin is validated against observed streamflow measurements for the period of 1994-2003. The climate projections from RCMs are then input to the VIC hydrologic model to simulate runoff and streamflow due to climate change under two emissions scenarios. The projected impacts on daily total runoff and monthly river discharge in the Athabasca River basin are further developed and investigated. It is our intention that changes of future climatological and hydrological patterns over the Athabasca River basin presented here will assist decision-makers in developing long-term water resources management plans and watershed-scale climate adaptation strategies.

\section{Methods}

\section{a. Study area}

The Athabasca River has its headwaters in the Columbia Icefield of the Rocky Mountains of the province of 


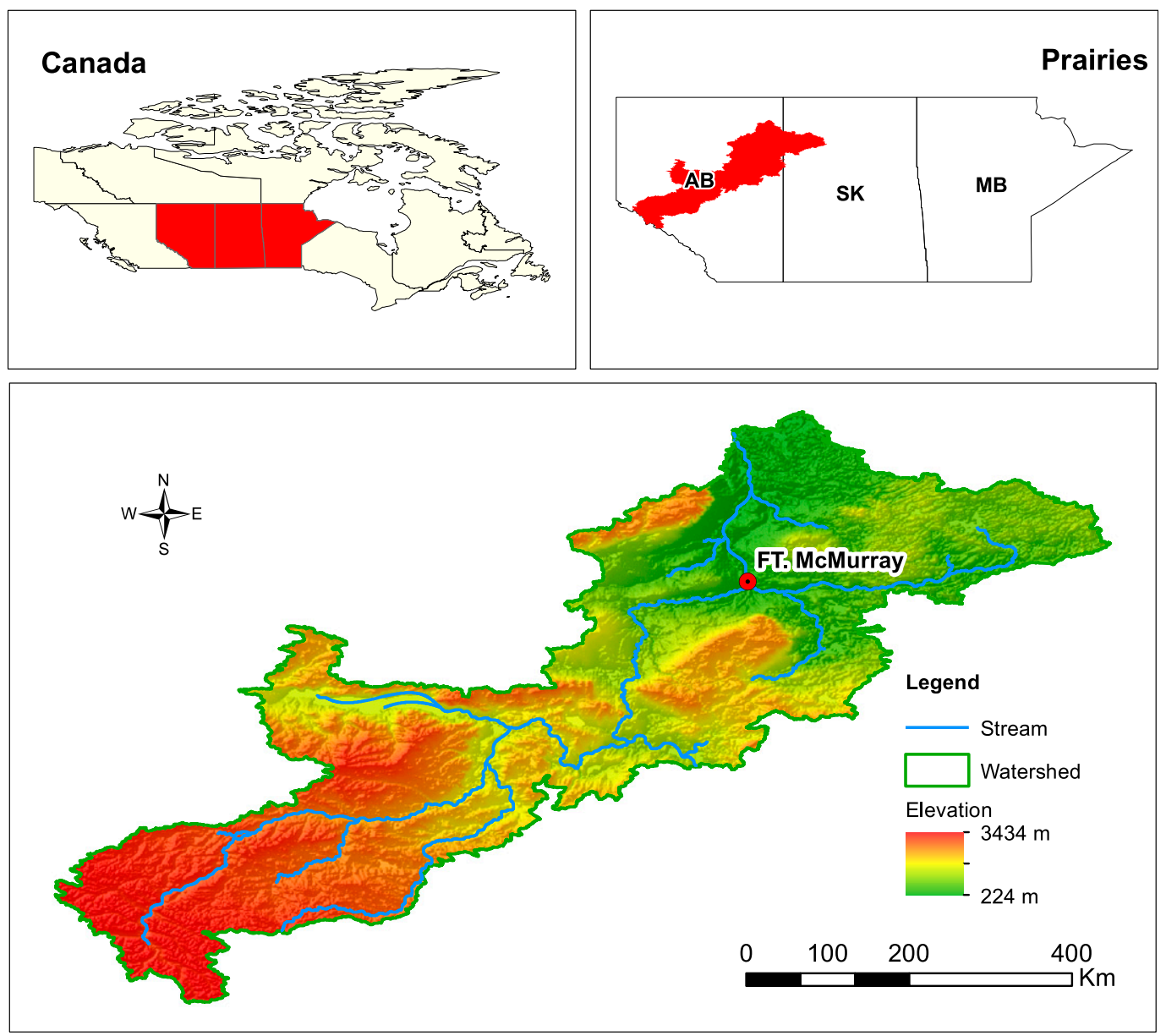

FIG. 1. Location and elevation of the Athabasca River basin.

Alberta, Canada (Eum et al. 2014). At $1500 \mathrm{~km}$ in length, it is the longest undammed river in Alberta and drains a total surface area of $156000 \mathrm{~km}^{2}$ (Fig. 1). The elevation of the Athabasca River ranges from over $3400 \mathrm{~m}$ in the Rocky Mountains to $224 \mathrm{~m}$ where it drains into Lake Athabasca. The land cover in the Athabasca River basin is mainly composed of evergreen needleleaf forest, mixed forest, woodland, wooded grassland, cropland, deciduous broadleaf forest, grassland, and shrubland (Fig. 2a). The watershed includes various topsoil covers such as clay (light), silty clay, loam, sand, loamy sand, and small areas of sandy loam (Fig. 2b), while the subsoil cover is dominated by clay (light), loam, and loamy sand (Fig. 2c).

The upper watershed is mainly formed of mountainous topography and cryosphere-dominated hydrologic regimes, the middle watershed is composed of three major tributaries (McLeod, Pembina, and Lesser Slave), and the lower watershed consists of several smaller tributaries. The climate in the Athabasca River basin is affected by the climatic patterns in both the Rocky
Mountains and the Arctic. It is recognized that climate change will have significant impacts on water availability, wildfires, flooding frequencies, drought durations, and energy demands (Cheng et al. 2017). In the period of 1983-2003, the average daily maximum temperature varied between $-1^{\circ}$ and $10^{\circ} \mathrm{C}$, while the average daily minimum temperature ranged from $-8^{\circ}$ to $-2^{\circ} \mathrm{C}$ (Hutchinson et al. 2009). The mean daily total precipitation changed from 1.01 to $2.95 \mathrm{~mm}$ over the same period (Hutchinson et al. 2009). The highest mean daily total precipitation occurs in the upper watershed and is an important contributor to the water resources availability throughout the watershed.

Various industrial activities in northern Alberta, including electrical power generation, mining, and bitumen production/extraction, are significantly dependent on water from the Athabasca River (Cheng et al. 2017; Eum et al. 2017). Surface water consumption is dominated by the oil sands mining activities, threatening the health of aquatic habitats and downstream wetlands (Cheng et al. 2017). It is unclear how climate change will alter the 


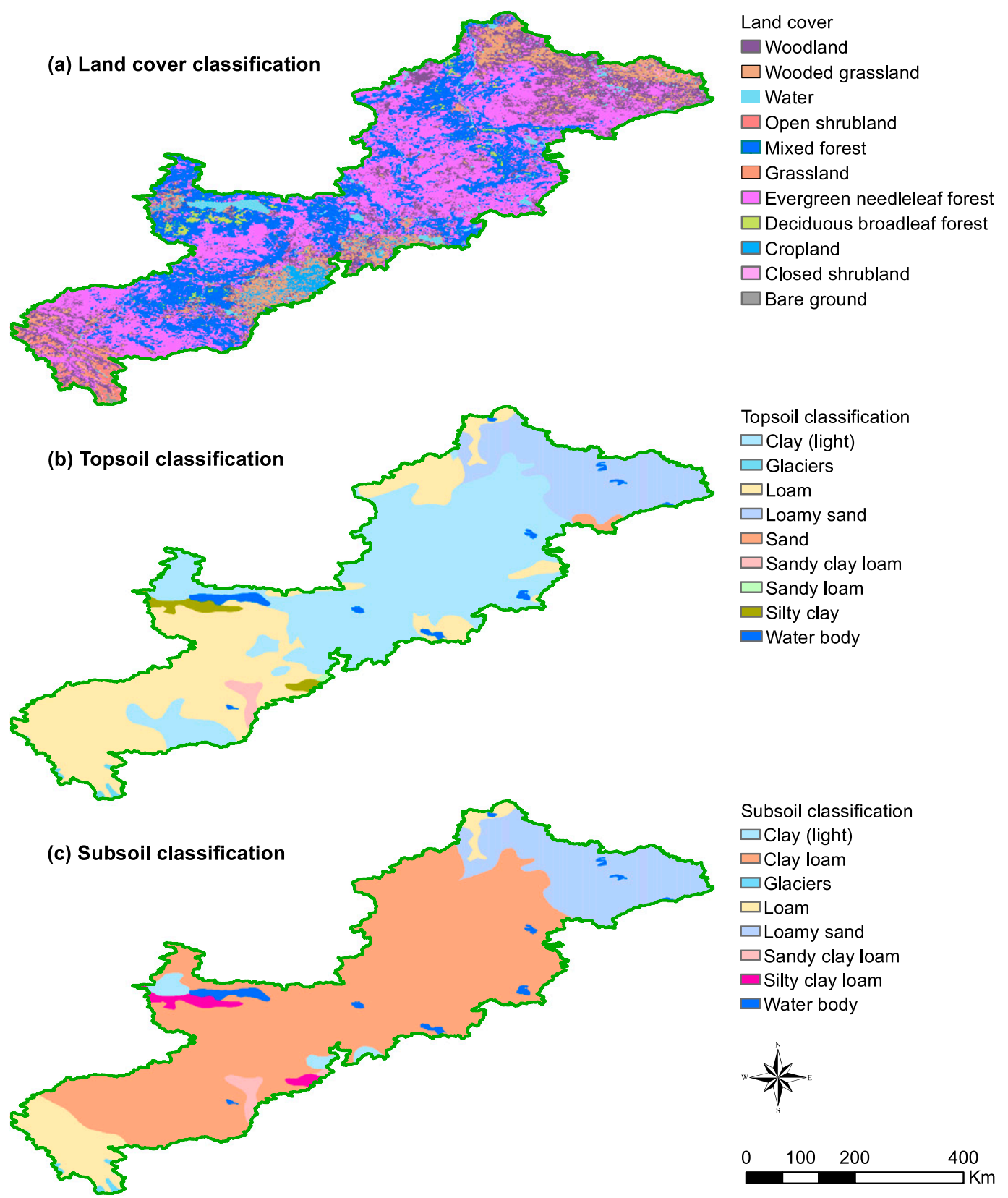

FIG. 2. (a)-(c) Land and soil cover classifications in the Athabasca River basin (FAO/IIASA/ISRIC/ISSCAS/JRC 2012; Hansen et al. 1998; Xiao et al. 2014).

hydrologic regime of the Athabasca River and impact the long-term management of water resources within its basin (Sauchyn et al. 2015).

\section{b. Data collection}

To calibrate and subsequently validate the PRECIS, RegCM, and VIC models, precipitation and temperature data for the Athabasca River basin were extracted from a 10-km gridded climate dataset obtained from the
National Land and Water Information Service (NLWIS), Agriculture and Agri-Food, Canada (NLWIS 2008). Wind data were obtained from the National Centers for Environmental Prediction-National Center for Atmospheric Research (NCEP-NCAR) reanalysis (Mesinger et al. 2006). In this study, daily maximum and minimum temperature, daily total precipitation, and daily mean wind speed for the period of 1984-2003 were used to represent the historical climate observations within the study area. 
The vegetation parameters and leaf area index (LAI) values were obtained from the AVHRR Global Land Cover Classification produced by the Department of Geography, University of Maryland (Hansen et al. 1998; Xiao et al. 2014). The soil parameters were retrieved from the Harmonized World Soil Database developed by the United Nations Food and Agriculture Organization (FAO/IIASA/ISRIC/ISSCAS/JRC 2012). The elevation datasets were obtained from the HydroSHEDS (Hydrological Data and Maps based on Shuttle Elevation Derivatives at Multiple Scales) database developed by the Conservation Science Program of the World Wildlife Fund (Lehner et al. 2006).

\section{c. Regional climate modeling using RCM}

PRECIS2.0 is the latest version of the regional climate modeling system developed by the Met Office Hadley Centre for Climate Science and Services, while the $\mathrm{RegCM}$ modeling system is version 4.6.0 from the International Center for Theoretical Physics (ICTP). They were employed to develop high-resolution, physicallybased climate projections over the Athabasca River basin. Detailed parameterizations of PRECIS and RegCM are described by Zhou et al. (2018b) and Qin and Xie (2016), respectively. The PRECIS and RegCM model are designed to provide detailed regional climate change projections for impact studies in the Athabasca River basin.

In this study, RCM ensemble simulations were implemented at a horizontal resolution of $0.22^{\circ} \times 0.22^{\circ}$ (i.e., approximately $25 \mathrm{~km}$ ) driven by boundary data from the HadGEM2-ES, CanESM2, and GFDL-ESM2M historical experiments to reproduce the baseline climate conditions. RCMs require a spatial domain of at least $100 \times 100$ grid cells to produce stable results. We ran our model extending out from the Athabasca River basin, spanning an area covering parts of the Prairie Provinces of Alberta, Saskatchewan, and Manitoba (108 longitude $\times$ 128 latitude grid points). The performance of RCMs in hindcasting the historical climatology was validated through comparisons with the NLWIS and NARR gridded dataset.

PRECIS and RegCM were used to forecast future climates for two different representative concentration pathway (RCP) climate change scenarios. The RCP4.5 scenario is one where global efforts to stabilize greenhouse gas (GHG) emissions, population growth, and land use conversions are successful over the next 80 years (Clarke et al. 2007; Smith and Wigley 2006; Wise et al. 2009). Alternatively, RCP8.5 describes a worst-case future scenario of unabated GHG emissions resulting from growing global population and minimal efforts at controlling energy demands (Riahi et al. 2007, 2011). These scenarios were chosen to demonstrate the range of possible hydrologic outcomes that can be expected for the Athabasca watershed.

\section{d. Hydrologic modeling using VIC}

We employed the VIC model to simulate the hydrologic response in the Athabasca River basin to climate inputs from RCMs (Liang et al. 1994). The VIC model has been employed extensively to assess impacts of climate change on hydrologic regimes for various watersheds in a variety of studies (Eum et al. 2017; Rajagopal et al. 2014; Schnorbus and Cannon 2014; Shrestha et al. 2014a). It was originally developed to couple with GCM simulations (Liang et al. 1994, 1996). Variable infiltration curves are used to represent the spatial heterogeneity of surface runoff generation (Naz et al. 2016). The model is able to represent subgrid variability of topography, vegetation, and precipitation, as well as soil moisture processes in three soil layers (Naz et al. 2016). The runoff field of the Athabasca River basin is derived by using an offline routing model, which is based on a linearized Saint-Venant equation (Lohmann et al. 1996). A more detailed description of the VIC model is presented by Liang et al. $(1994,1996)$.

In this study, we used the VIC model to calculate water and energy balances separately for each grid cell so that the regional spatial variability of present and future hydrologic responses in the Athabasca River basin could be evaluated. The VIC model for the Athabasca River basin was set up at $0.22^{\circ} \times 0.22^{\circ}$ to match the horizontal resolution of RCMs. To examine the effects of the initial soil moisture, we extracted the moisture content of each soil layer in a large number of points, which are spatially distributed across the Athabasca River basin. We find that a 3-yr spinup period is long enough to establish a stable moisture content of each soil layer. Therefore, following a 3 -yr spinup period from 1981 to 1983 (Demirel and Moradkhani 2014; Murdock 2017; Shrestha et al. 2014a), the VIC hydrologic model for the Athabasca watershed was calibrated and validated in the periods 1984-93 and 1994-2003, respectively. The mean values and standard deviations of daily maximum and minimum temperature, daily total precipitation, and daily mean wind speed over the Athabasca River basin for validation periods are similar to the datasets in the calibration periods.

The SCE-UA (Duan et al. 1994) was employed to calibrate the VIC model for the Athabasca River basin. The SCE-UA has been shown to be an effective global optimization method for calibrating hydrologic models (Muttil and Jayawardena 2008). Specifically, a set of six soil parameters, including the variable infiltration curve parameter $B_{i}(0-1)$, the fraction of maximum soil moisture $W_{s}(0-1)$, the maximum velocity of base flow 
$D_{s \max }(0-30)$, the fraction of $D_{s \max }\left(D_{s} ; 0-1\right)$, and the second and third soil layer depths $d_{2}$ and $d_{3}(0.1-1.5$ and $0.1-2$, respectively), were considered for the calibration. For each parameter set tested, all the grid cells in the Athabasca River basin are first modeled through VIC, and then the fluxes are collected and routed downstream by the offline routing model to calculate the objective function. Moreover, the detailed parameterization of the SCE-UA is set as follows: maximum number of iterations $m(m=10000)$, number of points in each complex $n(n=14)$, number of points in a subcomplex $s(s=10)$, and number of complexes $p(p=10)$.

The performance of the calibrated parameters was evaluated through comparison of the simulated streamflow to the monthly discharge data by using five hydrological metrics, including the Nash-Sutcliffe coefficient of efficiency (NSE), the normalized root-mean-square error (NRMSE), the normalized root-mean-square error of log-transformed streamflow (LRMSE), the RMSEobservations standard deviation ratio (RSR), and the percent bias (PBIAS). LRMSE puts more concern on the low flow, while NSE emphasizes the peak flow (Eum et al. 2017; Wagener et al. 2009). According to previous studies (Eum et al. 2017; Moriasi et al. 2007; Wagener et al. 2009), these hydrological metrics are defined in the following equations:

$$
\begin{aligned}
& \mathrm{NSE}=1-\sum_{t=1}^{T}\left(Q_{\mathrm{obs}, t}-Q_{\mathrm{sim}, t}\right)^{2} / \sum_{t=1}^{T}\left(Q_{\mathrm{obs}, t}-\bar{Q}_{\mathrm{obs}}\right)^{2}, \\
& \mathrm{NRMSE}=\sqrt{\sum_{t=1}^{T}\left(Q_{\mathrm{obs}, t}-Q_{\mathrm{sim}, t}\right)^{2} / \sum_{t=1}^{T} Q_{\mathrm{obs}, t}^{2}}
\end{aligned}
$$

LRMSE $=\sqrt{\sum_{t=1}^{T}\left(\log Q_{\mathrm{obs}, t}-\log Q_{\mathrm{sim}, t}\right)^{2} / \sum_{t=1}^{T}\left(\log Q_{\mathrm{obs}, t}\right)^{2}}$,

$\mathrm{RSR}=\sqrt{\sum_{t=1}^{T}\left(Q_{\mathrm{obs}, t}-Q_{\mathrm{sim}, t}\right)^{2} / \sum_{t=1}^{T}\left(Q_{\mathrm{obs}, t}-\bar{Q}_{\mathrm{obs}}\right)^{2}}, \quad$ and

$\operatorname{PBIAS}=\sum_{t=1}^{T}\left(Q_{\mathrm{obs}, t}-Q_{\mathrm{sim}, t}\right) \times 100 / \sum_{t=1}^{T} Q_{\mathrm{obs}, t}$,

where $Q_{\text {obs }, t}$ and $Q_{\text {sim }, t}$ are the $t$ th observed and simulated streamflow, respectively; $\bar{Q}_{\mathrm{obs}}$ is the mean of observations; and $T$ is the total number of time steps.

The validated VIC model was then employed to reproduce the baseline streamflow (i.e., 1984-2003) for the Athabasca River basin driven by the historical PRECIS and $\mathrm{RegCM}$ simulations of daily maximum and minimum temperature, daily total precipitation, and daily mean wind speed. The projected ensemble streamflows for the Athabasca River basin under the RCP4.5 and RCP8.5 climate change scenarios for the period 2006-99 were then developed through the validated VIC model using ensemble temperature, precipitation, and wind speed projections.

\section{Results}

\section{a. Validation of ensemble RCM simulations}

To assess the performance of RCMs in hindcasting historical climate in the context of the Athabasca River basin, daily maximum temperature, daily minimum temperature, and daily accumulated precipitation during the baseline period were extracted from the RCM simulations. These data were then used to calculate the average daily total precipitation, daily maximum temperature, daily minimum temperature, and daily mean wind speed in the historical period of 1984-2003, which could be employed to validate the performance of RCMs in reproducing historical annual cycles within the Athabasca River basin. The validation results of the daily total precipitation, maximum temperature, minimum temperature, and mean wind speed are presented in Fig. 3.

Although there is a small warming bias in the PRECIS simulation driven by HadGEM2-ES (hereinafter referred as HA-PRECIS) over the middle of the Athabasca River watershed, the daily maximum temperature from the NLWIS dataset was well captured by the HA-PRECIS simulation. The overall difference over the watershed was $+1.6^{\circ} \mathrm{C}$. However, the performance of the HA-PRECIS simulation in hindcasting the observed means in daily minimum temperature was not as effective as that for daily maximum temperature, with a bias of $+3 \cdot 1^{\circ} \mathrm{C}$. The daily total precipitation simulated by the HA-PRECIS model overestimated the NLWIS data by $0.03 \mathrm{~mm}$ overall, with higher variability in the glaciated regions accounting for most of the differences. However, the daily mean wind speed was underestimated by $0.5 \mathrm{~m} \mathrm{~s}^{-1}$ relative to the NARR observations. Given that the magnitudes of these overestimates and underestimates were all within the ranges of root-mean-square errors of the NLWIS and NARR data (Hutchinson et al. 2009; Mesinger et al. 2006), the performance of PRECIS in hindcasting the historical climatology was affirmed.

However, the performance of RegCM simulations driven by CanESM2 (hereinafter referred as CA-RegCM) and GFDL-ESM2M (hereinafter referred as GF-RegCM) are not effective as PRECIS in reproducing the observer means for the four variables. For example, it can be found that CA-RegCM tends to overestimate the daily 
Daily maximum temperature
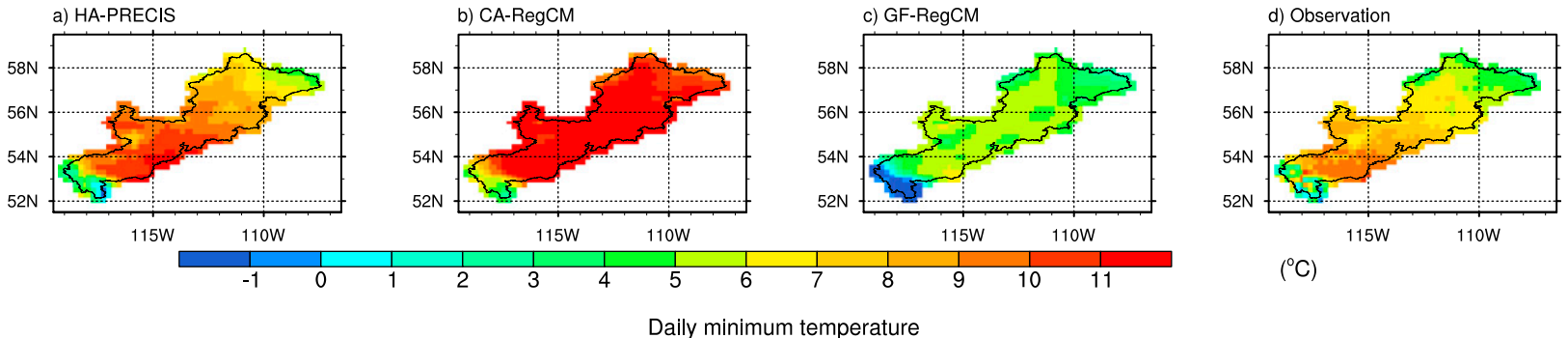

$\left({ }^{\circ} \mathrm{C}\right)$
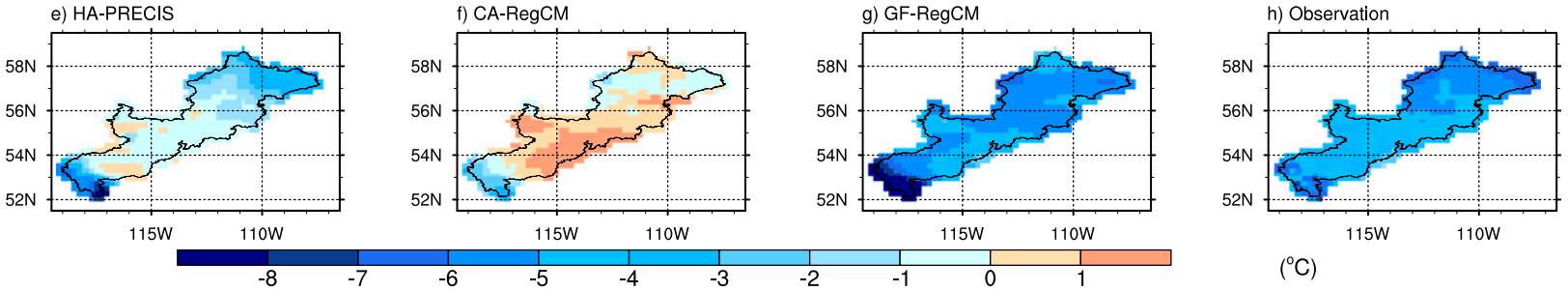

$\left({ }^{\circ} \mathrm{C}\right)$

Daily total precipitation
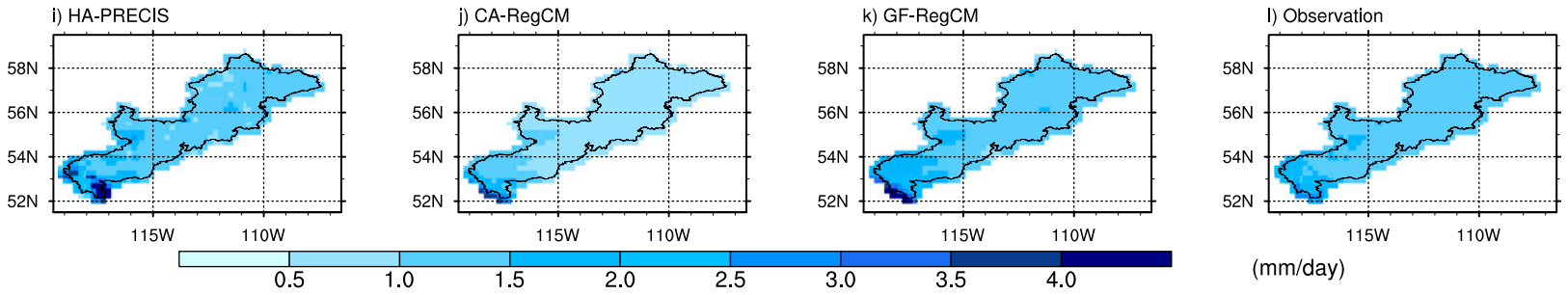

Daily mean wind speed
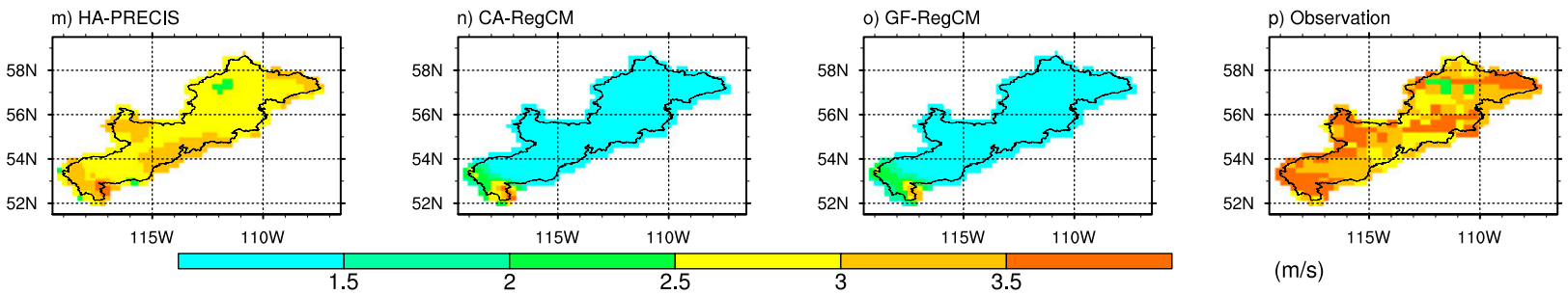

FIG. 3. Validation of temperature, precipitation, and wind speed for 1984-2003 from HA-PRECIS (i.e., PRECIS driven by HadGEM2-ES), CA-RegCM (i.e., RegCM driven by CanESM2), GF-RegCM (i.e., RegCM driven by GFDL-ESM2M), and observations.

maximum temperature and daily minimum temperature, while they are underestimated from GF-RegCM. The two RegCM simulations can reasonably well reproduce the daily total precipitation except for a small wet bias in southwestern sections of the watershed. Moreover, they simulate much lower daily mean wind speed with an averaged bias of $2.4 \mathrm{~m} \mathrm{~s}^{-1}$.

Moreover, the dynamical downscaling approach is compared to the bias-corrected spatial disaggregation (BCSD), which is an efficient statistical downscaling and spatial disaggregation method (Eum et al. 2017; Eum and Cannon 2017). It can be seen that BCSD simulations driven by HadGEM2-ES, CanESM2, and GFDL-ESM2M well reproduced the daily maximum temperature, daily minimum temperature, and daily total precipitation, with a slight cold bias in temperature and a slight wet bias in precipitation (Fig. 4). However, the magnitude and spatial pattern of daily wind mean speed are not simulated well from the BCSD method.

To further investigate the performance of dynamical downscaling and statistical downscaling models, two precipitation extreme indices (i.e., CDD and R95pTOT) derived from the Expert Team on Climate Change Detection and Indices are employed in this study. CDD is defined as annual maximum number of consecutive days with precipitation less than $1 \mathrm{~mm}$, while R95pTOT is the annual total precipitation when precipitation is larger than the 95th percentile of precipitation 
Daily maximum temperature
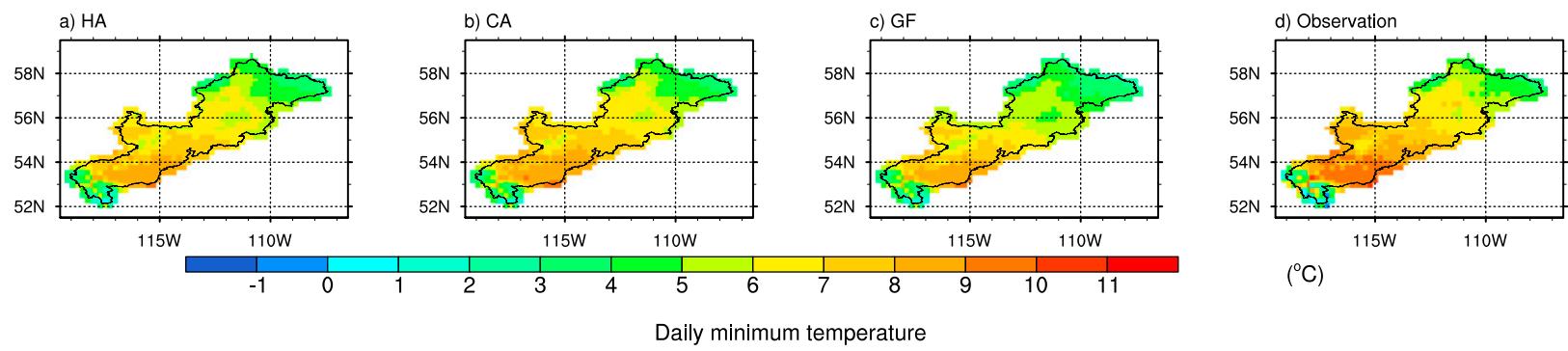

$\left({ }^{\circ} \mathrm{C}\right)$
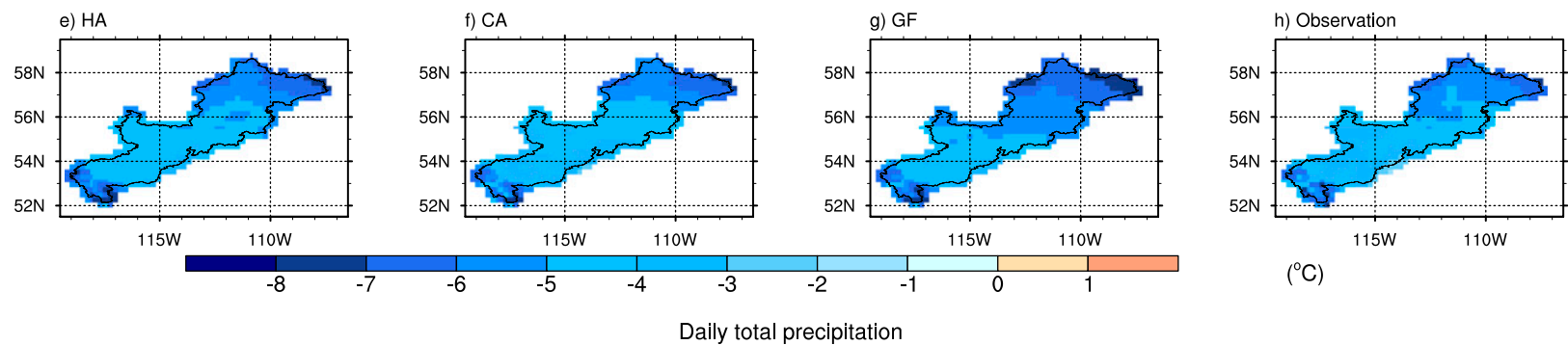

Daily total precipitation
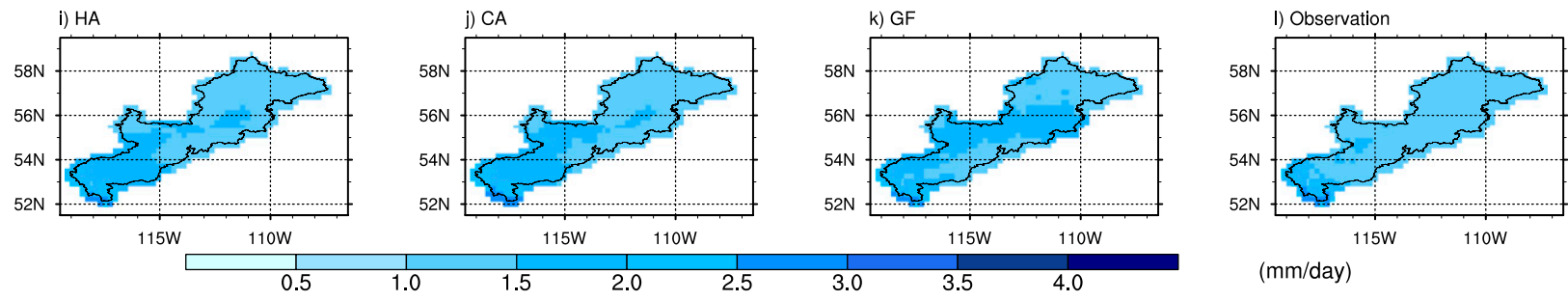

Daily mean wind speed
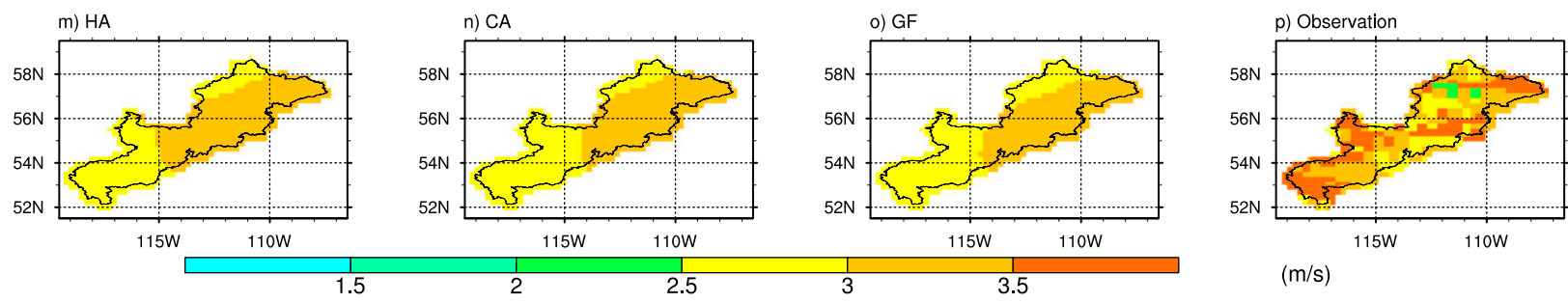

FIG. 4. Validation of temperature, precipitation, and wind speed for 1984-2003 from BCSD driven by HA (i.e., HadGEM2-ES), CA (i.e., CanESM2), GF (i.e., GFDL-ESM2M), and observations.

(Zhou et al. 2018c). As shown in Fig. 5, we find that dynamical downscaling outperforms the BCSD method with respect to the magnitudes and spatial patterns of the two selected precipitation extremes. This is mainly because the two selected precipitation extremes are not directly calibrated by the BCSD methods. In contrast, dynamical downscaling based on physical mechanisms similar to GCMs to resolve more local detailed features can be more skillful to reproduce the precipitation and temperature extremes.

Overall, the evaluation results indicate that the range bounded by the maximum and minimum of ensemble RCM simulations can capture the historical climatological patterns of daily total precipitation, daily maximum temperature, daily minimum temperature, and daily mean wind speed reasonably well. It can also demonstrate that the ensemble RCM simulations can be more skillful in reproducing the two selected precipitation extremes, which can be expected in simulating temperature and wind extremes. This can be attributed to more detailed topography, land use/cover, and soil types in the ensemble RCM simulations that are based on physical mechanisms. Therefore, in this study, we choose RCMs to generate ensemble downscaled climate projections from HadGEM2-ES, CanESM2, and GFDL-ESM2M in order to investigate the impacts of future climate change on the hydrologic regimes in the Athabasca River basin. 

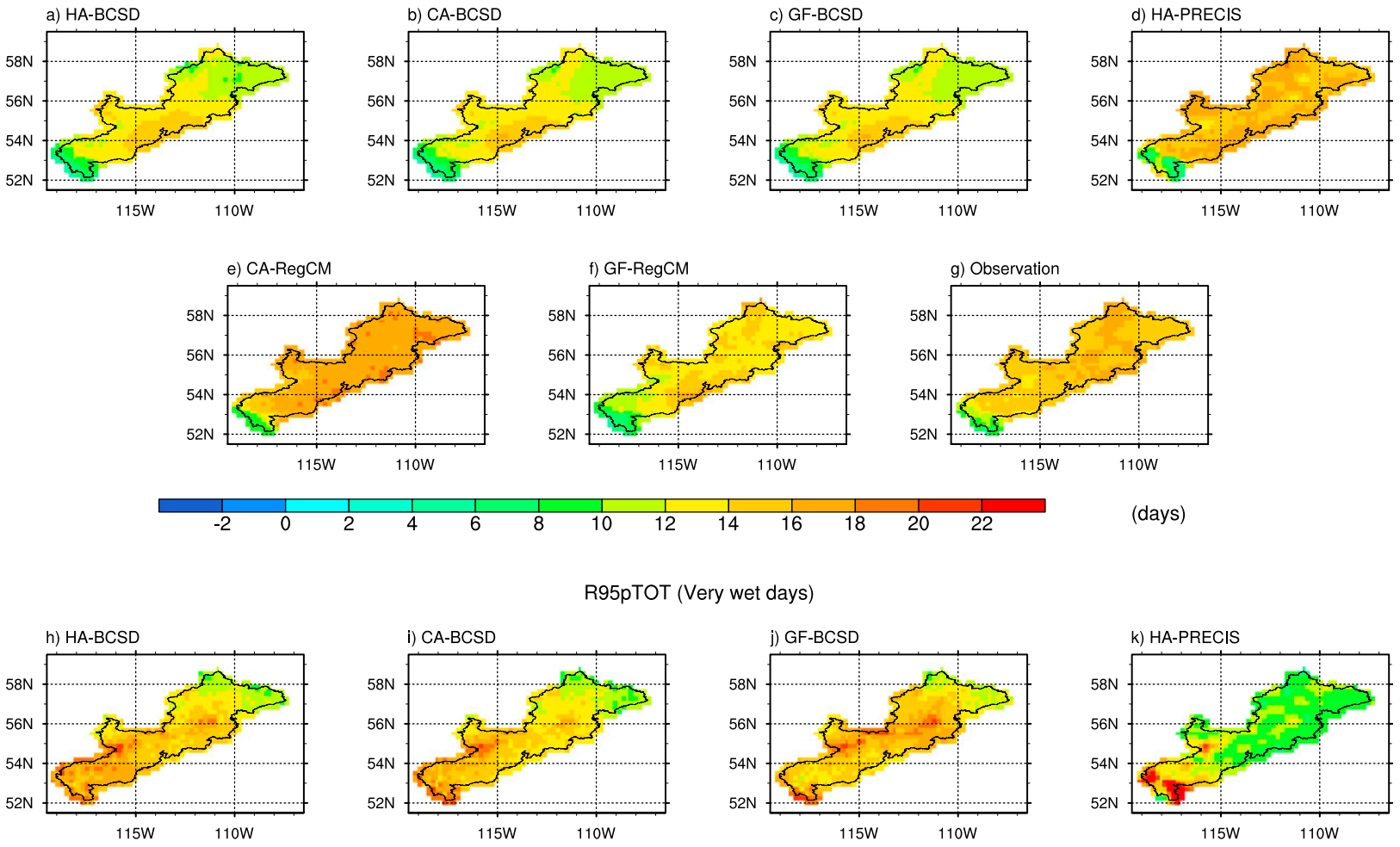

R95pTOT (Very wet days)
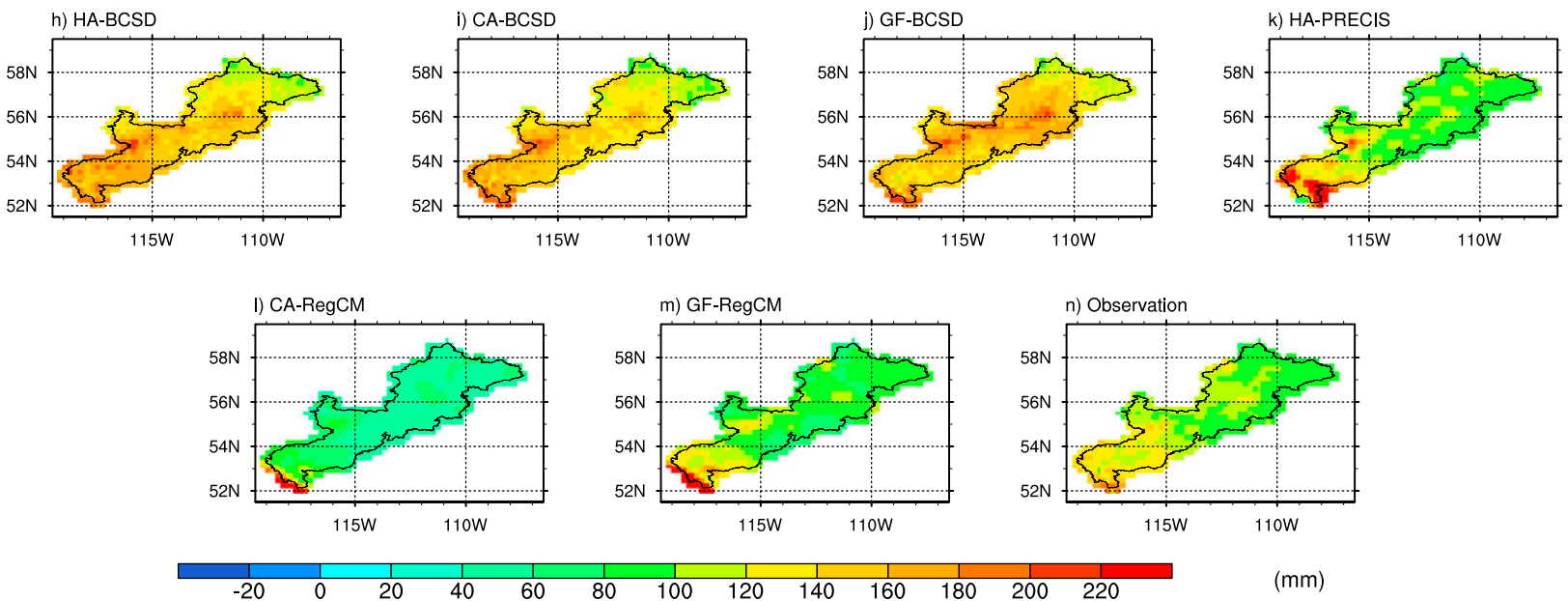

FIG. 5. Validation of precipitation extremes for 1984-2003 from the dynamical and statistical downscaling approach as well as observations.

\section{b. VIC hydrologic model validation for the Athabasca River basin}

To validate the ability of the VIC model in replicating the characteristic of the observed streamflow in the Athabasca River basin, the modeled outputs at Ft. McMurray were compared to the monthly mean observations (Fig. 6). The results show good agreement between the observed and simulated streamflow, with the monthly discharge peaks well captured by the VIC model. The peak flows during the validation period were simulated very well, but there were slight difficulties in reproducing peak flows during the calibration period. The VIC modeled streamflow can simulate low flows in the winter period from November to February reasonably well.

Table 1 presents the evaluation results for the performance of the VIC model during the calibration and validation period. For example, the NSE values for the calibration and validation periods were 0.845 and 0.800 , respectively. As shown in the table, the RSR values are less than 0.50 and the PBIAS values are less than $\pm 20 \%$, while the NSE coefficients are larger than 0.75 , thus affirming the good performance of the VIC model in the Athabasca River basin for both calibration and validation periods (Moriasi et al. 2007). Moreover, as seen from relatively low values of LRMSE (i.e., 0.063 and 0.082 ), low flows are reasonably reproduced during the calibration and verification period.

Overall, the results showed that the VIC model was able to well replicate the dynamics and seasonality of the observed streamflow for both calibration and validation periods, and hence the validated VIC model was employed to project hydrologic conditions driven by the 


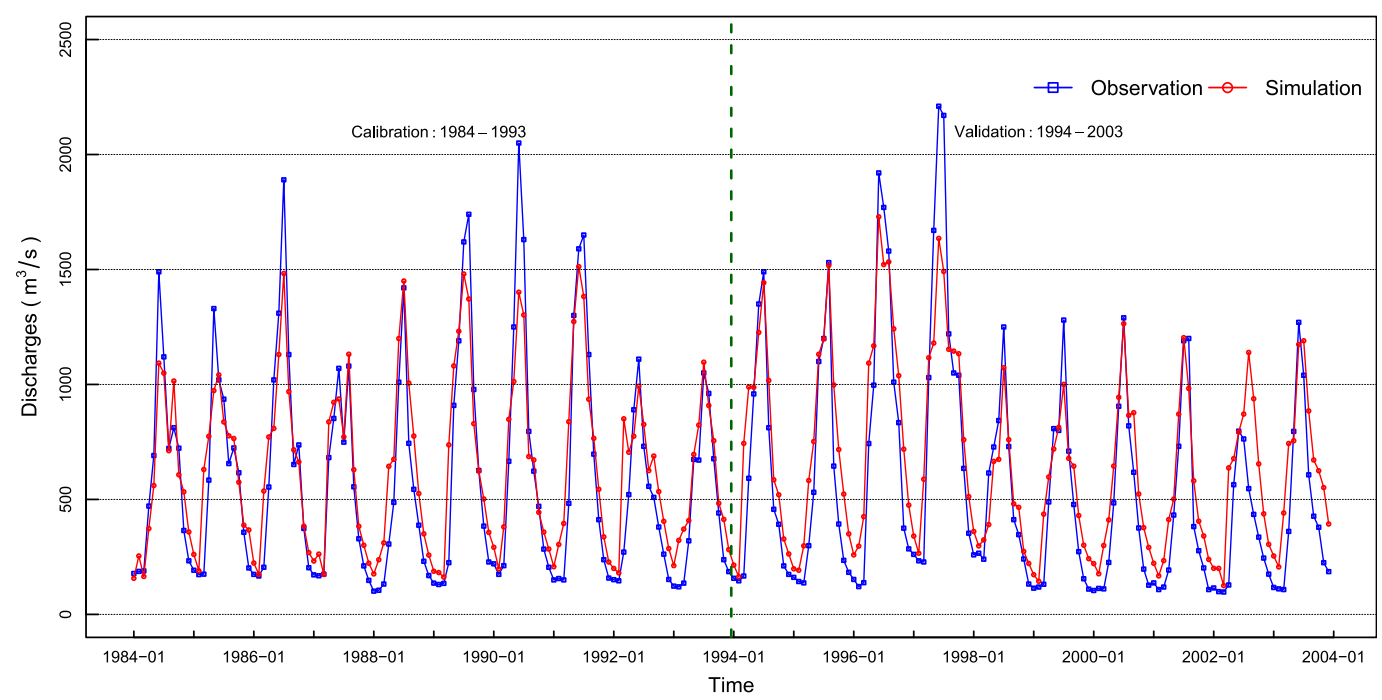

FIG. 6. Simulated and observed monthly streamflow at Ft. McMurray $\left(56^{\circ} 43^{\prime} \mathrm{N}, 111^{\circ} 22^{\prime} \mathrm{W}\right)$.

ensemble RCM simulations under different RCP climate scenarios.

\section{c. Projected changes in temperature and precipitation}

The validated RCMs were used to develop ensemble climate projections driven by HadGEM2-ES, CanESM2, and GFDL-ESM2M for 2006-99 under the RCP4.5 and RCP8.5 scenarios. To understand how climate will change, the projections were divided into two 20 -yr periods: 2050s (2046-65) and 2080s (2076-95). Mean value and standard deviation of changes in daily maximum temperature, daily minimum temperature, daily total precipitation, and daily mean wind speed relative the baseline period (i.e., 1984-2003) were calculated and analyzed under the two RCPs.

The projected changes in daily maximum temperature for the two future periods (i.e., the 2050s and 2080s) under both RCP4.5 and RCP8.5 reveal a consistently increasing trend in the ensemble RCM simulations under RCPs for two future periods over the entirety of the Athabasca River basin (Fig. 7). The range of projected mean values for changes in daily maximum temperature for the 2050s under RCP4.5 is $2.1^{\circ}-2.7^{\circ} \mathrm{C}$, while the range for the $2080 \mathrm{~s}$ is $2.5^{\circ}-3.5^{\circ} \mathrm{C}$. These increases are expected to be higher in the lower reach of the watershed. As seen from much higher standard deviations, there are larger uncertainties associated with the upper reaches for two future periods under the RCPs.
The ensemble RCM simulations also show that the daily maximum temperatures are expected to be $1^{\circ}-3^{\circ} \mathrm{C}$ higher in RCP8.5 climates than in RCP4.5 scenarios. This is indicative of the increased sensitivity of future projections to higher GHG concentrations.

Figure 8 shows the projected changes in the average daily minimum temperature in the Athabasca River basin for the 2050s and 2080s. Daily minimum temperatures under the RCP4.5 climate scenario are expected to increase by more than $2.8^{\circ} \mathrm{C}$ for the $2050 \mathrm{~s}$ and $3.5^{\circ} \mathrm{C}$ for the 2080s, with higher increases at the northern end of the watershed. A similar pattern is evident for the RCP8.5 scenario, except with even bigger changes. For instance, the largest increase in daily minimum temperature under RCP8.5 for the 2050s is projected to be $3.9^{\circ} \mathrm{C}$, while the projected largest increase for the $2080 \mathrm{~s}$ is $6.7^{\circ} \mathrm{C}$ in the northern Athabasca River. Moreover, RCM simulations project larger uncertainties in the upper and lower reaches, suggesting that there is a substantial intermodel variability in the ensemble RCM simulations under both RCP4.5 and RCP8.5.

The ensemble RCM simulations project increases in the daily total precipitation over the majority of the Athabasca River basin under both RCP climate scenarios for the 2050s and 2080s (Fig. 9). Decreases are evident in the southwestern sections of the watershed under RCP4.5 for the 2050s and 2080s. For instance, the daily total precipitation over the majority of the

TABLE 1. Evaluations of the VIC model for the calibration and validation periods.

\begin{tabular}{lcccrr}
\hline \hline Period & NSE & NRMSE & LRMSE & RSR & PBIAS \\
\hline Calibration & 0.845 & 0.247 & 0.063 & 0.394 & -7.842 \\
Verification & 0.800 & 0.281 & 0.082 & 0.447 & -18.506 \\
\hline
\end{tabular}


a) RCP4.5: 2050s (Mean)

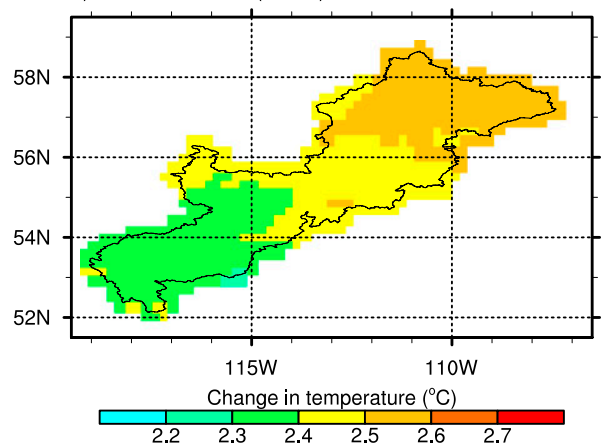

c) RCP4.5: 2080s (Mean)

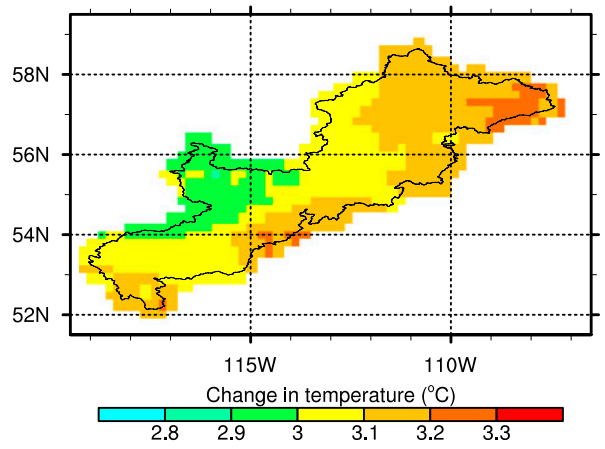

e) RCP8.5: 2050s (Mean)

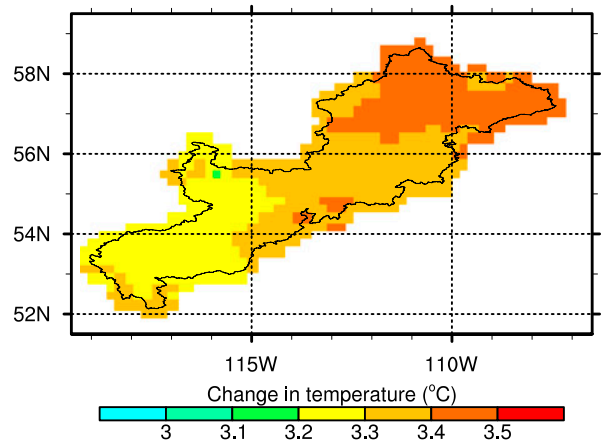

g) RCP8.5: 2080s (Mean)

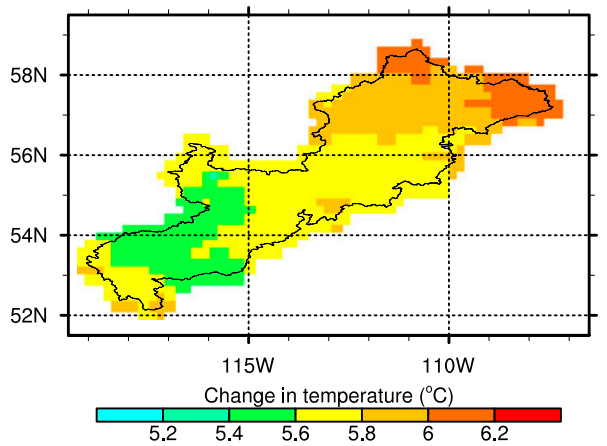

b) RCP4.5: 2050s (Standard deviation)

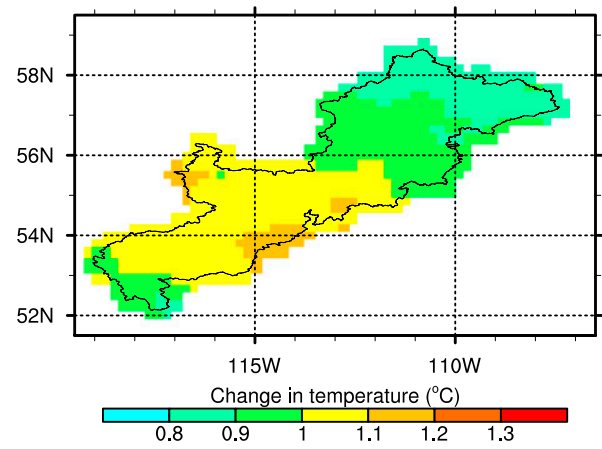

d) RCP4.5: 2080s (Standard deviation)

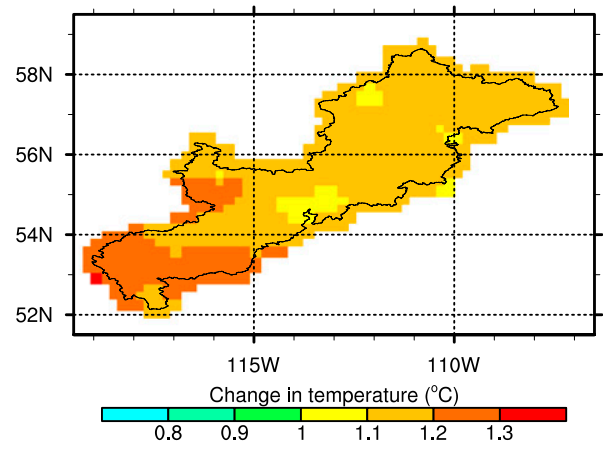

f) RCP8.5: 2050s (Standard deviation)

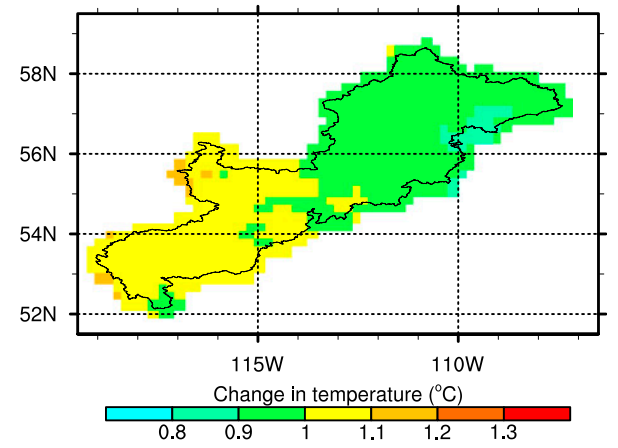

h) RCP8.5: 2080s (Standard deviation)

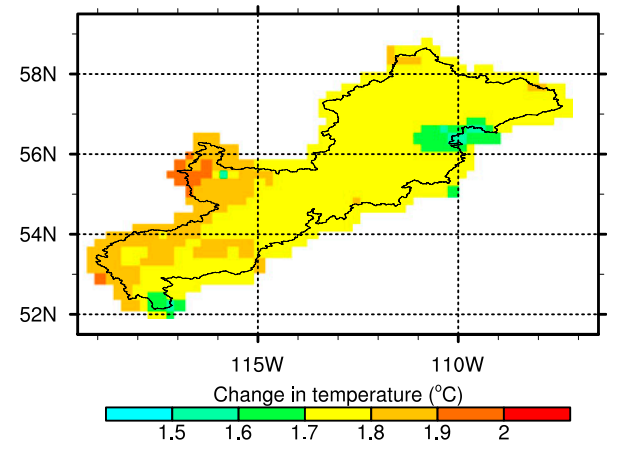

FIG. 7. Projected changes in daily maximum temperature for the 2050s and 2080s under different RCP climate scenarios. 
a) RCP4.5: 2050s (Mean)

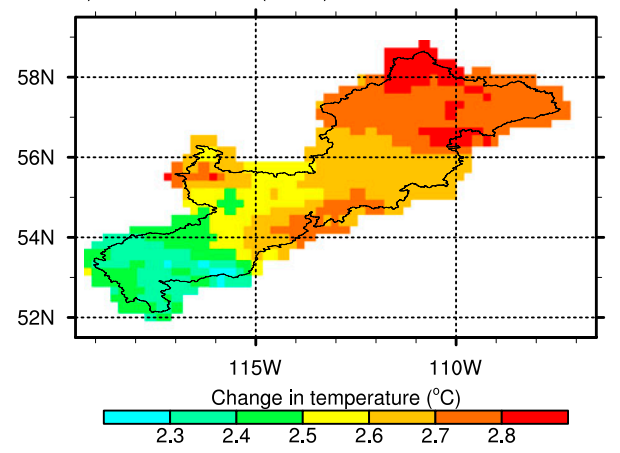

c) RCP4.5: 2080s (Mean)

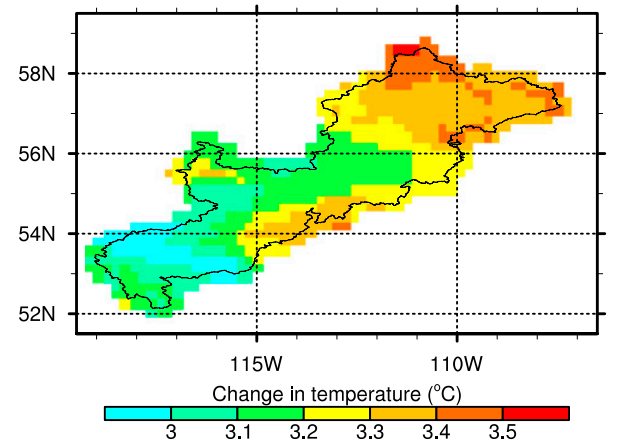

e) RCP8.5: 2050s (Mean)

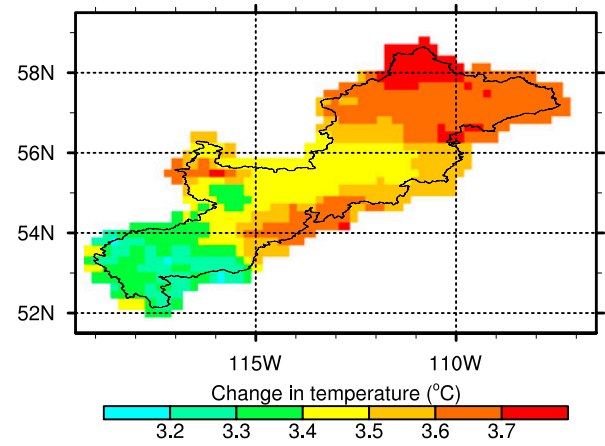

g) RCP8.5: 2080s (Mean)

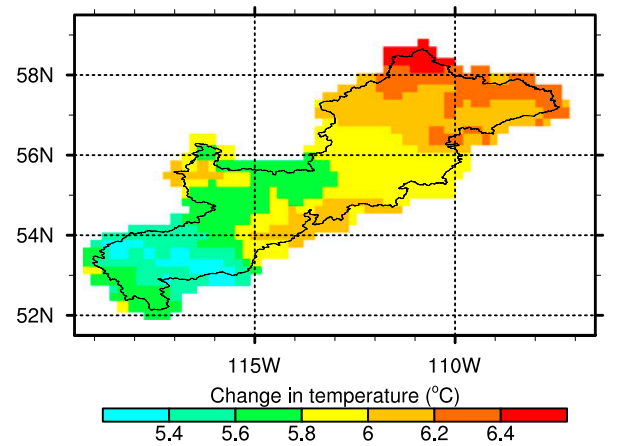

b) RCP4.5: 2050s (Standard deviation)

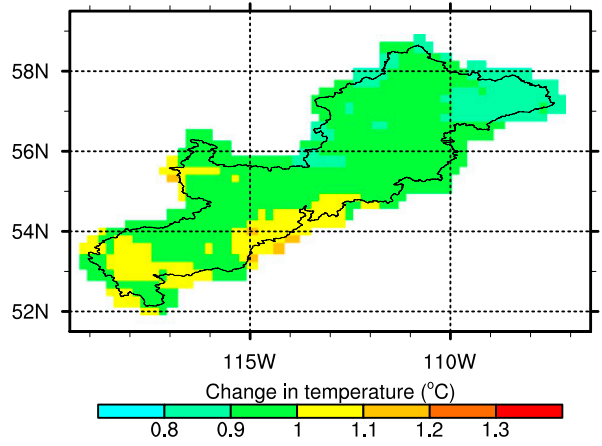

d) RCP4.5: 2080s (Standard deviation)

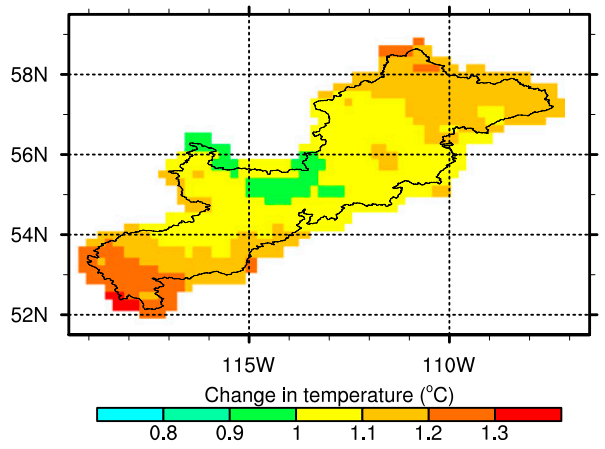

f) RCP8.5: 2050s (Standard deviation)

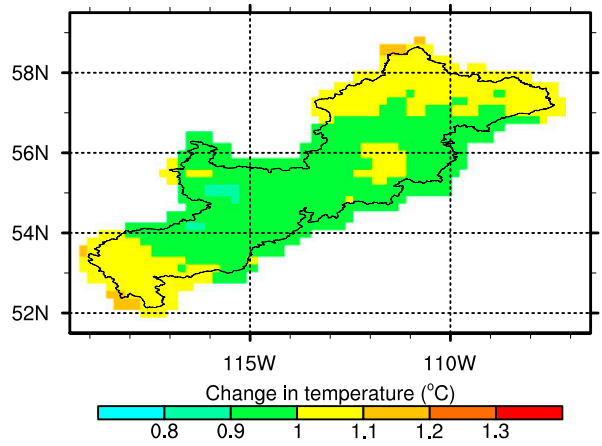

h) RCP8.5: 2080s (Standard deviation)

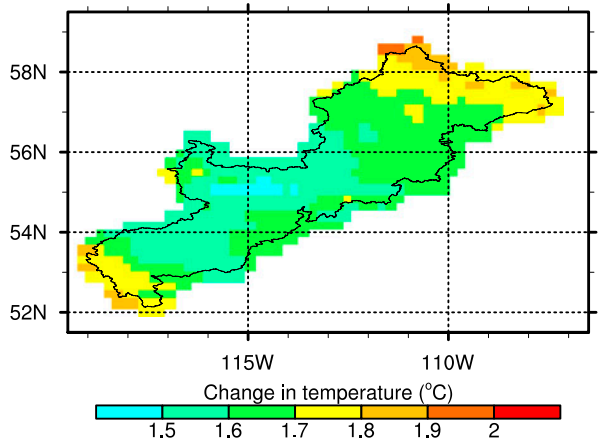

FIG. 8. Projected changes in daily minimum temperature for the 2050s and 2080s under different RCP climate scenarios. 
a) RCP4.5: 2050s (Mean)

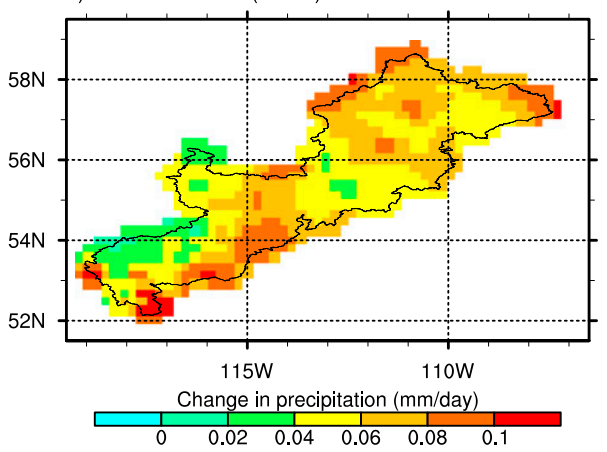

C) RCP4.5: 2080s (Mean)

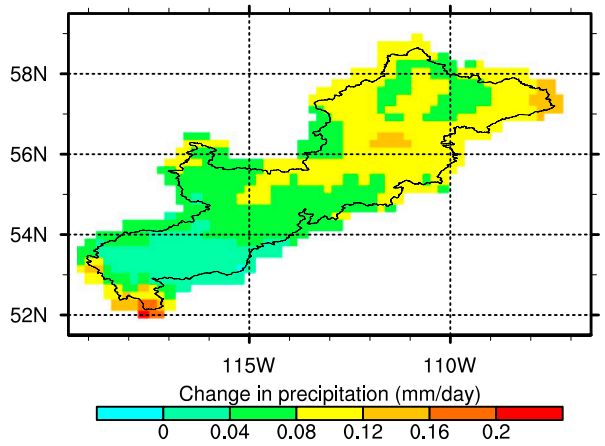

e) RCP8.5: 2050s (Mean)

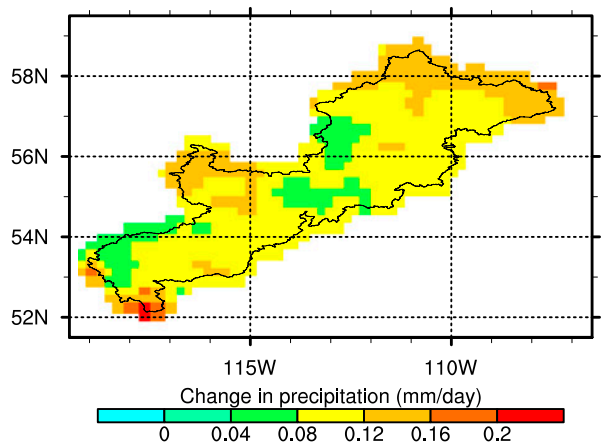

g) RCP8.5: 2080s (Mean)

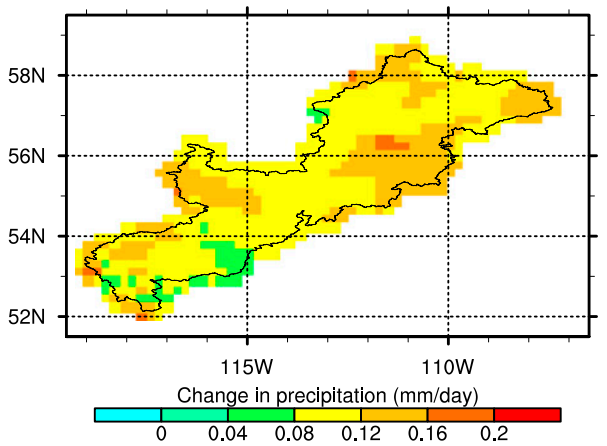

b) RCP4.5: 2050s (Standard deviation)

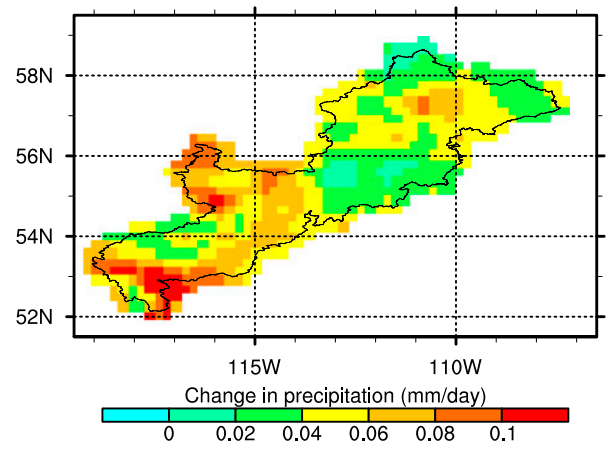

d) RCP4.5: 2080s (Standard deviation)

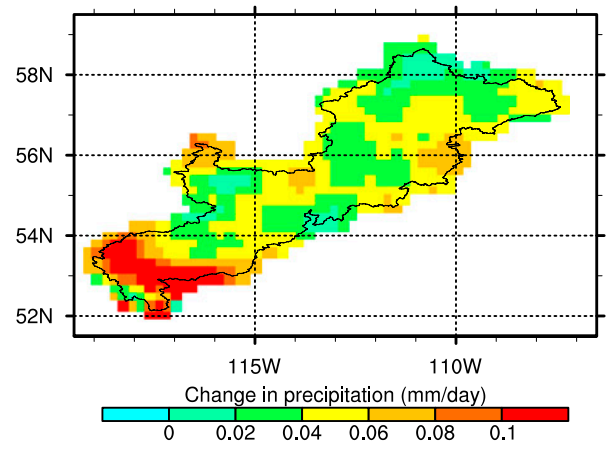

f) RCP8.5: 2050s (Standard deviation)

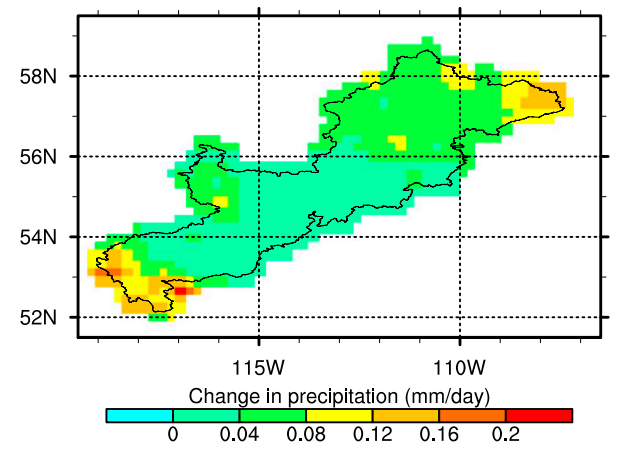

h) RCP8.5: 2080s (Standard deviation)

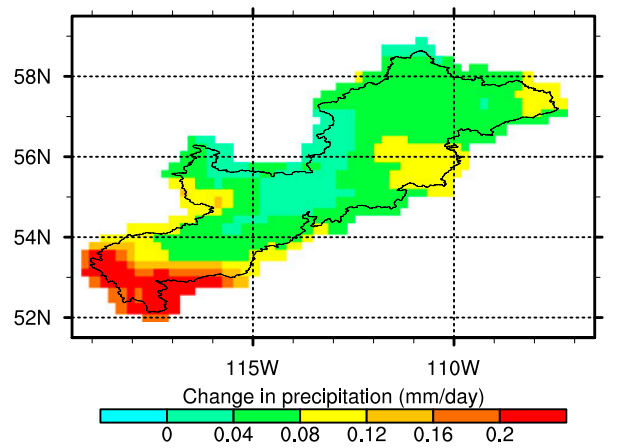

FIG. 9. Projected changes in daily total precipitation for the 2050s and 2080s under different RCP climate scenarios. 
Athabasca River basin is projected to be an increase of as much as $0.21 \mathrm{~mm}$ under RCP8.5 for the $2050 \mathrm{~s}$, which is expected to occur in the upper watershed. Nevertheless, the projected decrease in daily total precipitation will be as low $0.03 \mathrm{~mm}$, which is projected in the southern basin. This reveals that the RCM simulations tend to project the highest increases in the upper and lower watersheds, while the largest decrease is also projected in the upper watershed of the Athabasca River basin. The projected change in daily total precipitation also demonstrates larger uncertainties in the upper watershed than the projected increase in the middle and lower watersheds.

Figure 10 shows the projected changes in daily mean wind speed for the two future periods under both RCP climate scenarios. The results indicate that there is a consistently increasing trend in the magnitudes of the projected wind speed over the majority of the Athabasca River basin, with a maximum increase of $0.13 \mathrm{~m} \mathrm{~s}^{-1}$ in the lower reach. These increases are projected to be slightly higher in the middle and lower reaches of the watershed. Moreover, the projected decreases in daily wind speed under RCP8.5 for the 2080s are augmented, implying that climate change under RCP8.5 for the 2080s is more unpredictable than that under RCP4.5 for the 2050s (Deser et al. 2012; Wang et al. 2015a). Larger levels of uncertainties are projected in the upper and lower reaches under RCPs for two future time periods.

\section{d. Hydrologic effects of climate change}

The results of the ensemble RCM modeling driven by HadGEM2-ES, CanESM2, and GFDL-ESM2M for the two RCP climate scenarios were input to the VIC model and used to examine the hydrologic effects of climate change on water resources in the Athabasca River basin for the period 2006-99. To provide a better understanding of possible changes in runoff and streamflow under the RCP scenarios, the analysis was split into two 20-yr periods: 2050s (2046-65) and 2080s (2076-95).

Figure 11 shows the spatial variability of projected changes in daily total runoff relative to the baseline conditions (1984-2003). A general increase in daily total runoff is forecast. For example, the daily total runoff under RCP4.5 is projected to increase by as much as $0.10 \mathrm{~mm}$ in the $2050 \mathrm{~s}$, and $0.13 \mathrm{~mm}$ in the 2080s. Small areas of the upper watershed are projected to experience decreases in runoff under both RCP scenarios, essentially driven by similar decreases in the projected precipitation patterns. However, similar relationships between projected runoff and future maximum and minimum temperature were not evident. This suggests that there is a strong agreement between the projected changes in daily total precipitation and runoff in the Athabasca River basin. The results also indicate that larger levels of uncertainties from different boundary inputs and regional climate models exist in the upper reach.

Figure 12 shows the projected changes in average monthly streamflow at Ft. McMurray driven by HadGEM2-ES, CanESM2, and GFDL-ESM2M under the RCP4.5 and RCP8.5 climate scenarios for the two future periods. Increases are expected for all projections, except June-September for the 2080s. This is consistent with the projected changes in daily total runoff for the entire Athabasca River basin. Moreover, the results also indicate that larger increases are expected in the winter season (i.e., December-February) for the 2080s under the RCPs. This is mainly because of the compound effects of increased total precipitation combined with earlier snowmelt, due to the projected increases in maximum and minimum temperatures by RCMs. Increases in the spring streamflow as well as larger uncertainties in response to global warming are anticipated, since most of the flow at this time is from snowmelt in the upper reaches of the watershed.

\section{Conclusions}

In this study, an ensemble-RCM-driven VIC model has been developed to investigate climate change impacts on hydrologic regimes in the Athabasca River basin. The PRECIS and RegCM model were first used to develop ensemble high-resolution regional climate projections for the period of 1979-2099 over the Canadian Prairies, driven by the boundary conditions from HadGEM2-ES, CanESM2, and GFDL-ESM2M under two different RCP climate scenarios. The performance of ensemble RCM simulations was then validated through comparison with observed temperature and precipitation over the baseline period (1984-2003). Meanwhile, the macroscale VIC hydrologic model was calibrated for the period of 1984-93 in the Athabasca River basin using the SCE-UA method. The performance of the VIC model in replicating the characteristic of the observed streamflow in the Athabasca River basin was then validated for the period of 1994-2003. The validated VIC model was then employed to simulate runoff and streamflow for the period of 1979-2099 in the Athabasca River basin. Future climate changes and their impacts on daily total runoff and monthly river discharge in the Athabasca River basin were also investigated.

On the basis of the analysis of projected changes in temperature and precipitation under the RCPs, increasing trends over the entirety of the Athabasca River basin are anticipated for two future time periods, in the 2050s and 2080s. The largest increases in temperature are projected to occur in the northeast reaches of the watershed. The ensemble RCM simulations projected a 
a) RCP4.5: 2050s (Mean)

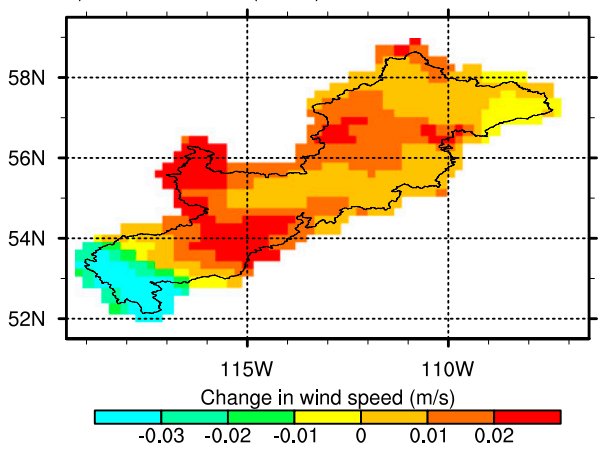

C) RCP4.5: 2080s (Mean)

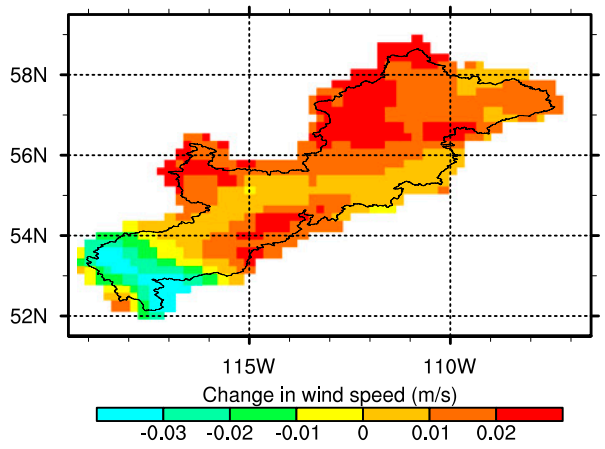

e) RCP8.5: 2050s (Mean)

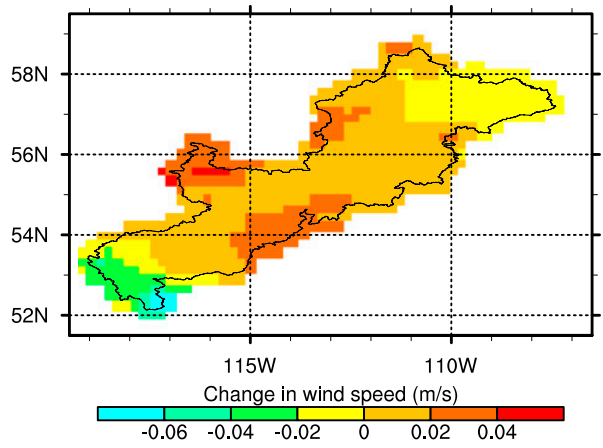

g) RCP8.5: 2080s (Mean)

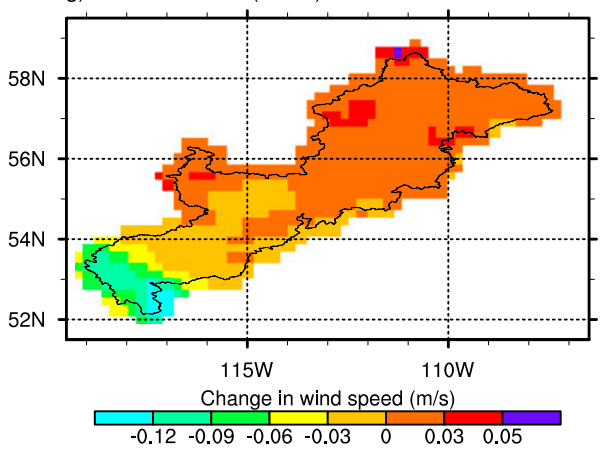

b) RCP4.5: 2050s (Standard deviation)

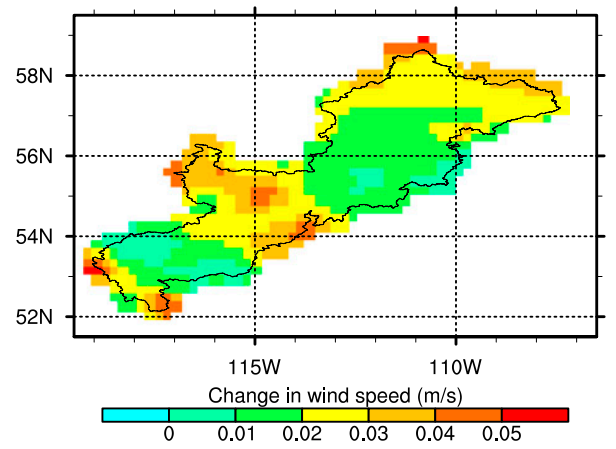

d) RCP4.5: 2080s (Standard deviation)

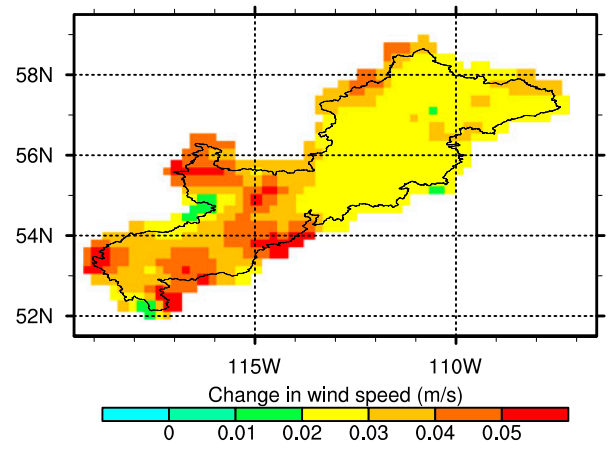

f) RCP8.5: 2050s (Standard deviation)

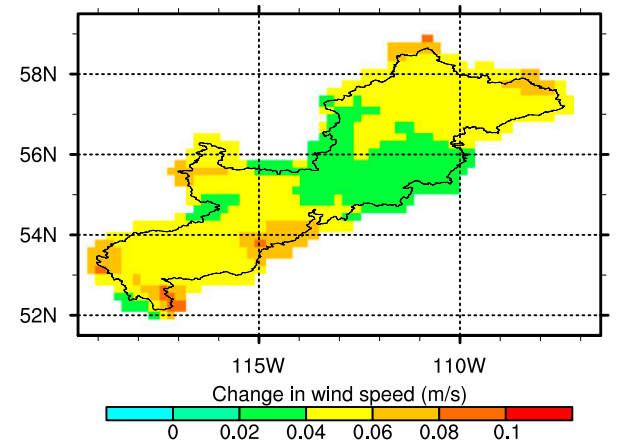

h) RCP8.5: 2080s (Standard deviation)

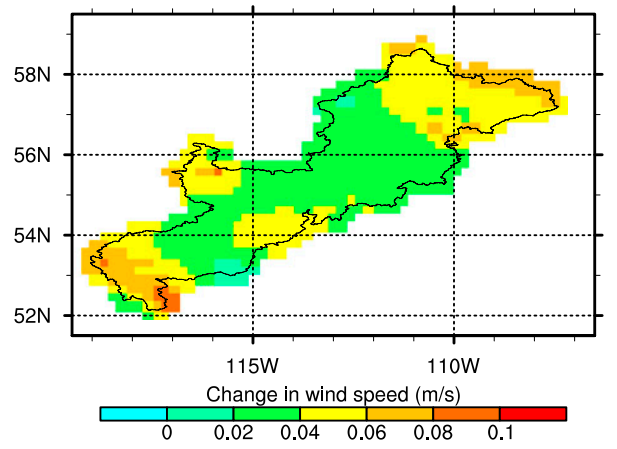

FIG. 10. Projected changes in daily mean wind speed for the 2050s and 2080s under different RCP climate scenarios. 
a) RCP4.5: 2050s (Mean)

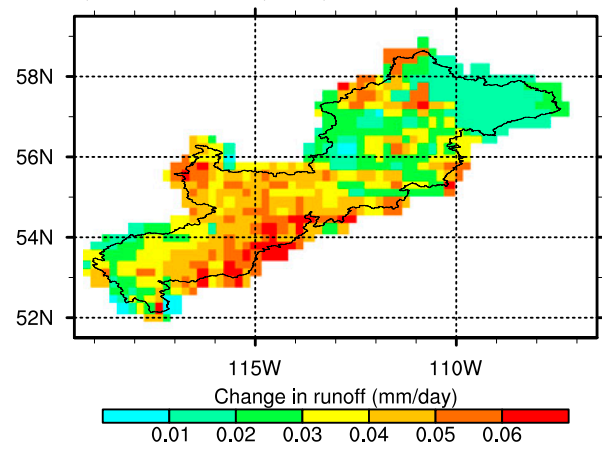

c) RCP4.5: 2080s (Mean)

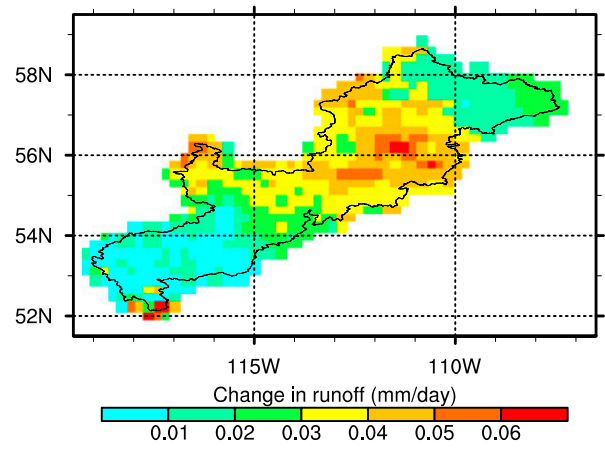

e) RCP8.5: 2050s (Mean)

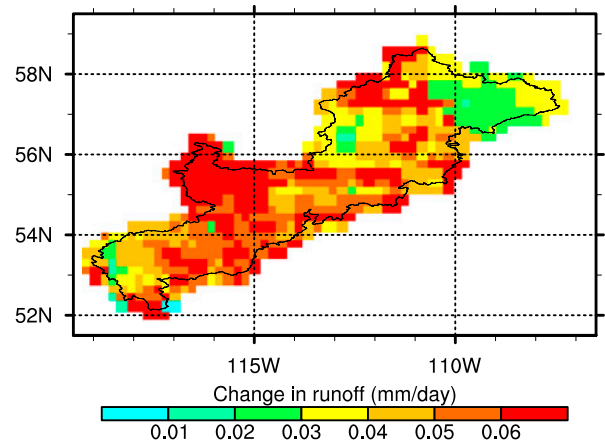

g) RCP8.5: 2080s (Mean)

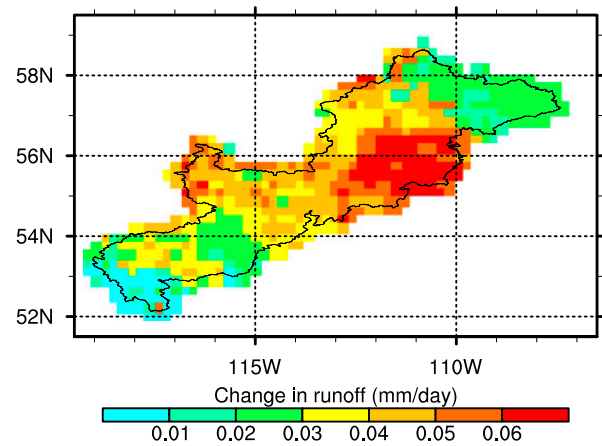

b) RCP4.5: 2050s (Standard deviation)

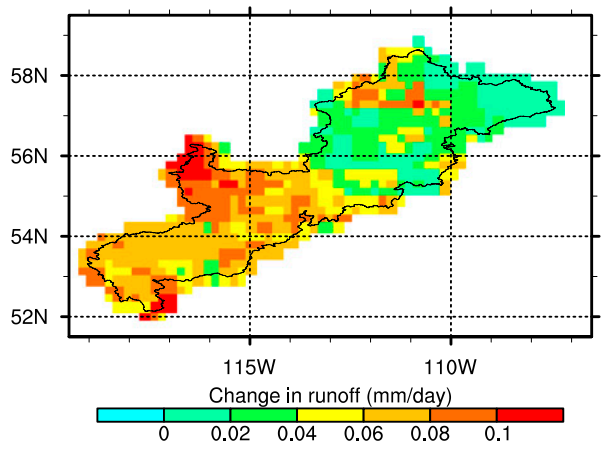

d) RCP4.5: 2080s (Standard deviation)

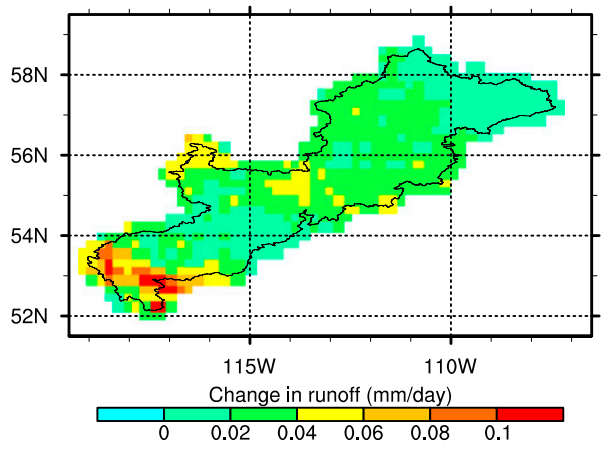

f) RCP8.5: 2050s (Standard deviation)

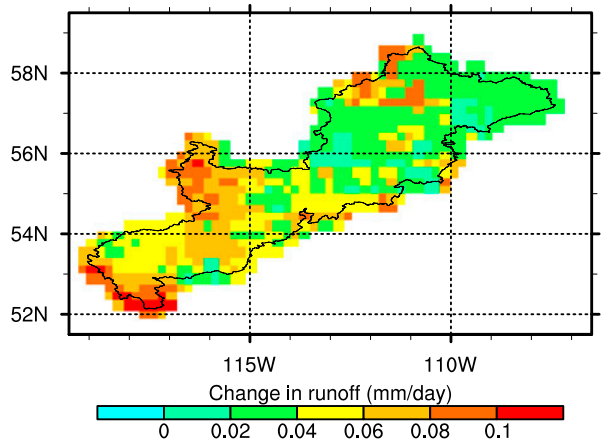

h) RCP8.5: 2080s (Standard deviation)

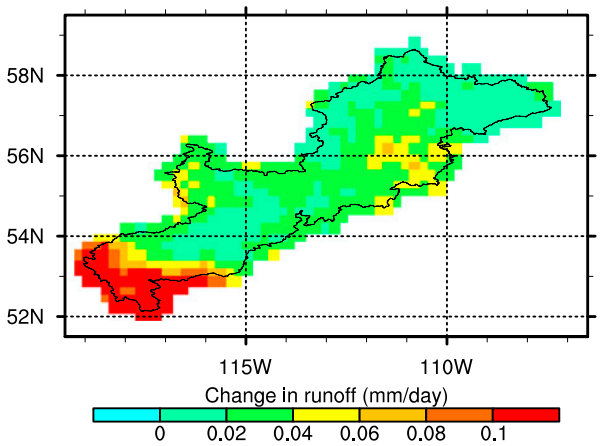

FIG. 11. Projected changes in daily total runoff for the 2050s and 2080s under different RCP climate scenarios. 
a) RCP45: 2050s

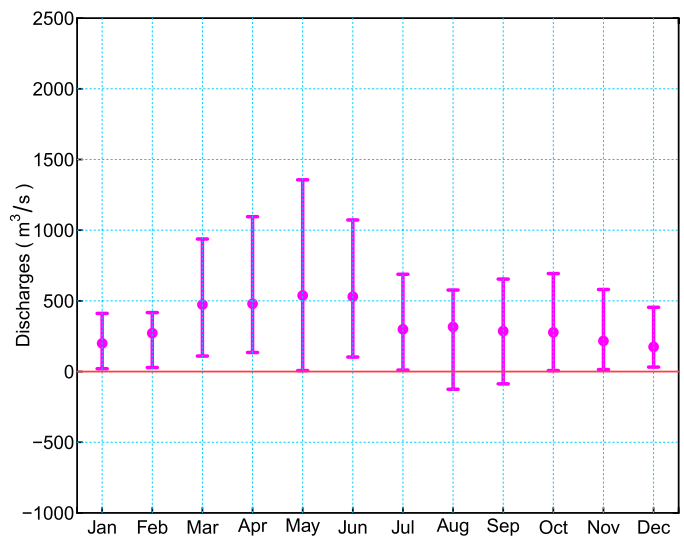

c) RCP85: 2050s

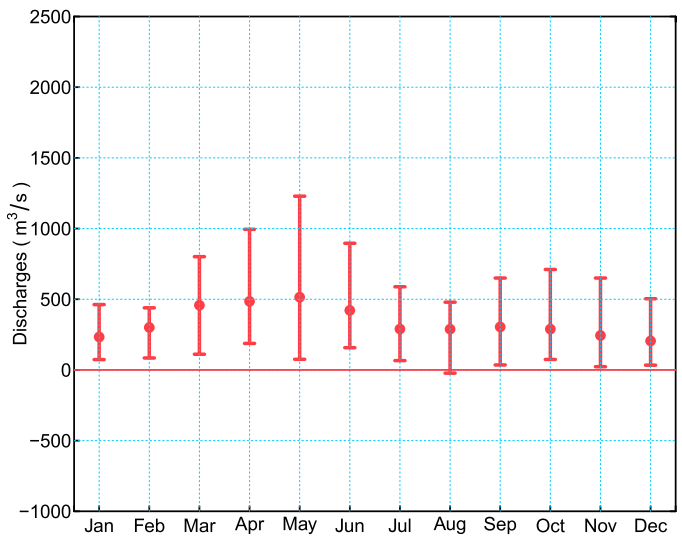

b) RCP45: 2080s

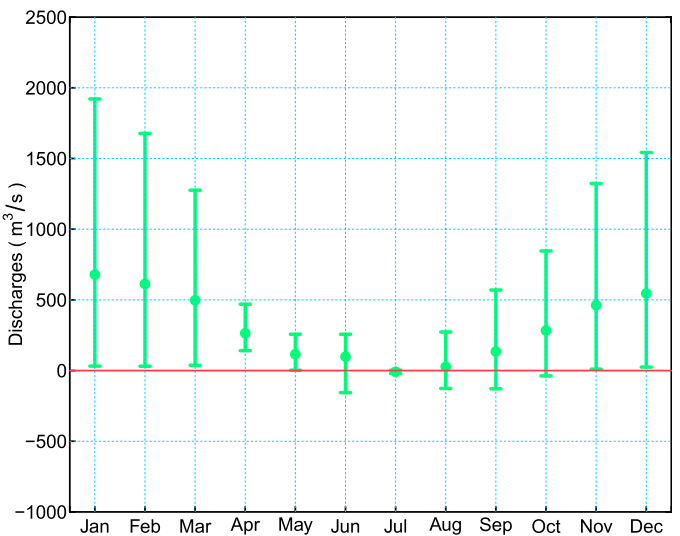

d) RCP85: 2080s

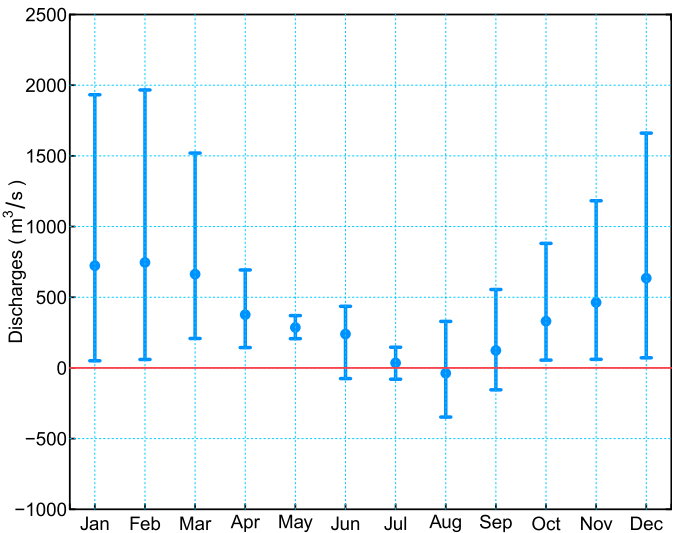

FIG. 12. Projected changes in monthly runoff at Ft. McMurray $\left(56^{\circ} 43^{\prime} \mathrm{N}, 111^{\circ} 22^{\prime} \mathrm{W}\right)$ under different $\mathrm{RCP}$ climate scenarios. The monthly streamflow means are displayed as round points, and the range bounded by the maximum and minimum of streamflow driven by the ensemble RCM simulations is indicated by the linear bar.

larger increase in daily minimum temperature than in daily maximum temperature. The daily total precipitation is also expected to be higher over the upper and lower sections of the Athabasca River basin. The upper reaches of the watershed are projected to experience a decrease in precipitation in the future. There is a consistently increasing trend in the magnitudes of the projected wind speed over the majority of the Athabasca River basin, with a maximum increase of $0.13 \mathrm{~m} \mathrm{~s}^{-1}$ in the lower reaches. Moreover, the results indicate that larger levels of uncertainties from different boundary inputs and regional climate models exist in the upper reach.

Analyses of the projected effects of climate change on the hydrologic regimes of the Athabasca River basin using the validated VIC model revealed that a general increase in daily total runoff could be expected in the upcoming decades. Monthly streamflow is projected to increase in the 2050s and 2080s for both RCP climate scenarios analyzed, with notably higher flows expected in the spring for the 2080s. Meanwhile, larger uncertainties associated with the spring streamflows for the 2080s in response to global warming are projected, since most of the flow at this time is from snowmelt in the upper reaches of the watershed.

This study proposed the ensemble-RCM-driven VIC model for assessing projected climate change impacts on local hydrologic regimes of the Athabasca River basin. The validation results demonstrate that the ensembleRCM-driven VIC model can effectively reproduce historical climatological and hydrological patterns of this watershed. We also find that the ensemble RCM simulations can be more skillful in reproducing the two selected precipitation extremes compared to BCSD, which can be expected in simulating temperature and wind extremes. The projected changes in temperature, precipitation, wind, runoff, and streamflow modeled here can be used to evaluate detailed regional impacts on aquatic habitat and downstream wetlands. To fully explore the uncertainties associated with the projected runoff, it is necessary to consider ensemble climate 
projections by employing multiple RCMs to downscale more GCMs, which would deserve future research efforts. Moreover, RCMs could be further coupled with statistical downscaling such as the BCSD method (Shrestha et al. 2014b). To reduce the computational time, a sparse grid calibration technique (Troy et al. 2008) could be employed in future studies.

Acknowledgments. This research was supported by the National Key Research and Development Plan (2016YFA0601502, 2016YFC0502800), the Natural Sciences Foundation (51520105013, 51679087), the 111 Program (B14008) and the Natural Science and Engineering Research Council of Canada.

\section{REFERENCES}

Cheng, G. H., G. H. Huang, C. Dong, J. X. Zhu, X. Zhou, and Y. Yao, 2017: An evaluation of CMIP5 GCM simulations over the Athabasca River basin, Canada. River Res. Appl., 33, 823843, https://doi.org/10.1002/rra.3136.

Cherkauer, K. A., and T. Sinha, 2010: Hydrologic impacts of projected future climate change in the Lake Michigan region. J. Great Lakes Res., 36, 33-50, https://doi.org/10.1016/ j.jglr.2009.11.012.

Clarke, L., J. Edmonds, H. Jacoby, H. Pitcher, J. Reilly, and R. Richels, 2007: Scenarios of greenhouse gas emissions and atmospheric concentrations. Synthesis and Assessment Product 2.1a, U.S. Climate Change Science Program, 154 pp., https:// science.energy.gov/ /media/ber/pdf/Sap_2_1a_final_all.pdf.

Demirel, M., and H. Moradkhani, 2014: Sensitivity of Columbia Basin runoff to long-term changes in multi-model CMIP5 precipitation simulations. 2014 Fall Meeting, San Francisco, CA, Amer. Geophys. Union, Abstract H23N-107.

Denis, B., R. Laprise, D. Caya, and J. Côté, 2002: Downscaling ability of one-way nested regional climate models: The BigBrother Experiment. Climate Dyn., 18, 627-646, https:// doi.org/10.1007/s00382-001-0201-0.

Deser, C., R. Knutti, S. Solomon, and A. S. Phillips, 2012: Communication of the role of natural variability in future North American climate. Nat. Climate Change, 2, 775-779, https:// doi.org/10.1038/nclimate1562.

Duan, Q., S. Sorooshian, and V. K. Gupta, 1994: Optimal use of the SCE-UA global optimization method for calibrating watershed models. J. Hydrol., 158, 265-284, https://doi.org/10.1016/ 0022-1694(94)90057-4.

Edwards, T. W., S. J. Birks, B. H. Luckman, and G. M. MacDonald, 2008: Climatic and hydrologic variability during the past millennium in the eastern Rocky Mountains and northern Great Plains of western Canada. Quat. Res., 70, 188-197, https:// doi.org/10.1016/j.yqres.2008.04.013.

Eum, H. I., and A. J. Cannon, 2017: Intercomparison of projected changes in climate extremes for South Korea: Application of trend preserving statistical downscaling methods to the CMIP5 ensemble. Int. J. Climatol., 37, 3381-3397, https:// doi.org/10.1002/joc. 4924 .

, D. Yonas, and T. Prowse, 2014: Uncertainty in modelling the hydrologic responses of a large watershed: A case study of the Athabasca River Basin, Canada. Hydrol. Processes, 28, 42724293, https://doi.org/10.1002/hyp.10230.
_, Y. Dibike, and T. Prowse, 2017: Climate-induced alteration of hydrologic indicators in the Athabasca River Basin, Alberta, Canada. J. Hydrol., 544, 327-342, https://doi.org/10.1016/ j.jhydrol.2016.11.034.

FAO/IIASA/ISRIC/ISSCAS/JRC, 2012: Harmonized World Soil Database (version 1.2). FAO and IIASA, accessed 14 February 2017, http://webarchive.iiasa.ac.at/Research/LUC/ExternalWorld-soil-database/HTML/index.html?sb=1.

Feser, F., B. Rockel, H. von Storch, J. Winterfeldt, and M. Zahn, 2011: Regional climate models add value to global model data: A review and selected examples. Bull. Amer. Meteor. Soc., 92, 1181-1192, https://doi.org/10.1175/2011BAMS3061.1.

Hansen, M., R. DeFries, J. R. Townshend, and R. Sohlberg, 1998: UMD global land cover classification, version 1.0. Subset used: 1 kilometer, 1981-1994. Department of Geography, University of Maryland, accessed 14 February 2017, http://glcf.umd. edu/data/landcover/.

Hutchinson, M. F., D. W. McKenney, K. Lawrence, J. H. Pedlar, R. F. Hopkinson, E. Milewska, and P. Papadopol, 2009: Development and testing of Canada-wide interpolated spatial models of daily minimum-maximum temperature and precipitation for 1961-2003. J. Appl. Meteor. Climatol., 48, 725-741, https://doi.org/10.1175/2008JAMC1979.1.

IPCC, 2013: Climate Change 2013: The Physical Science Basis. Cambridge University Press, 1535 pp., https://doi.org/10.1017/ CBO9781107415324.

Jones, R., J. Murphy, and M. Noguer, 1995: Simulation of climate change over Europe using a nested regional-climate model. I: Assessment of control climate, including sensitivity to location of lateral boundaries. Quart. J. Roy. Meteor. Soc., 121, 1413 1449, https://doi.org/10.1002/qj.49712152610.

_ M. Noguer, D. Hassell, D. Hudson, S. Wilson, G. Jenkins, and J. Mitchell, 2004: Generating high resolution climate change scenarios using PRECIS. Met Office Hadley Centre Rep., $35 \mathrm{pp}$.

Lehner, B., K. Verdin, and A. Jarvis, 2006: HydroSHEDS technical documentation, version 1.0. USGS Tech. Doc., 27 pp., https://hydrosheds.cr.usgs.gov/webappcontent/HydroSHEDS_ TechDoc_v10.pdf.

Liang, X., D. P. Lettenmaier, E. F. Wood, and S. J. Burges, 1994: A simple hydrologically based model of land surface water and energy fluxes for general circulation models. J. Geophys. Res., 99, 14 415-14 428, https://doi.org/10.1029/94JD00483.

—, E. F. Wood, and D. P. Lettenmaier, 1996: Surface soil moisture parameterization of the VIC-2L model: Evaluation and modification. Global Planet. Change, 13, 195-206, https:// doi.org/10.1016/0921-8181(95)00046-1.

Lohmann, D., R. Nolte-Holube, and E. Raschke, 1996: A largescale horizontal routing model to be coupled to land surface parametrization schemes. Tellus, 48A, 708-721, https:// doi.org/10.3402/tellusa.v48i5.12200.

Maurer, E. P., L. Brekke, T. Pruitt, and P. B. Duffy, 2007: Fineresolution climate projections enhance regional climate change impact studies. Eos, Trans. Amer. Geophys. Union, 88, 504-504, https://doi.org/10.1029/2007EO470006.

Mesinger, F., and Coauthors, 2006: North American Regional Reanalysis. Bull. Amer. Meteor. Soc., 87, 343-360, https:// doi.org/10.1175/BAMS-87-3-343.

Moriasi, D. N., J. G. Arnold, M. W. Van Liew, R. L. Bingner, R. D. Harmel, and T. L. Veith, 2007: Model evaluation guidelines for systematic quantification of accuracy in watershed simulations. Trans. ASABE, 50, 885-900, https://doi.org/ 10.13031/2013.23153. 
Murdock, E., 2017: Understanding local climate change impacts on water resources in southern Wisconsin, and the implications for managed intensive grazing. Ph.D. thesis, University of Wisconsin-Madison, $82 \mathrm{pp}$.

Muttil, N., and A. Jayawardena, 2008: Shuffled complex evolution model calibrating algorithm: Enhancing its robustness and efficiency. Hydrol. Processes, 22, 4628-4638, https://doi.org/ 10.1002/hyp.7082.

Naz, B. S., S.-C. Kao, M. Ashfaq, D. Rastogi, R. Mei, and L. C. Bowling, 2016: Regional hydrologic response to climate change in the conterminous United States using highresolution hydroclimate simulations. Global Planet. Change, 143, 100-117, https://doi.org/10.1016/j.gloplacha.2016.06.003.

Nijssen, B., G. M. O'Donnell, A. F. Hamlet, and D. P. Lettenmaier, 2001: Hydrologic sensitivity of global rivers to climate change. Climatic Change, 50, 143-175, https://doi.org/10.1023/ A:1010616428763.

NLWIS, 2008: Daily $10 \mathrm{~km}$ raster-gridded climate dataset for Canada, 1961-2003, version 1.0. National Land and Water Information Service, Agriculture and Agri-Food Canada, accessed 14 February 2017, https://www.mcgill.ca/library/find/maps/dgcd10km.

Özdogan, M., 2011: Climate change impacts on snow water availability in the Euphrates-Tigris basin. Hydrol. Earth Syst. Sci., 15, 2789, https://doi.org/10.5194/hess-15-2789-2011.

Qin, P., and Z. Xie, 2016: Detecting changes in future precipitation extremes over eight river basins in China using RegCM4 downscaling. J. Geophys. Res. Atmos., 121, 6802-6821, https:// doi.org/10.1002/2016JD024776.

Rajagopal, S., F. Dominguez, H. V. Gupta, P. A. Troch, and C. L. Castro, 2014: Physical mechanisms related to climate-induced drying of two semiarid watersheds in the southwestern United States. J. Hydrometeor., 15, 1404-1418, https://doi.org/ 10.1175/JHM-D-13-0106.1.

Raje, D., and R. Krishnan, 2012: Bayesian parameter uncertainty modeling in a macroscale hydrologic model and its impact on Indian river basin hydrology under climate change. Water Resour. Res., 48, W08522, https://doi.org/10.1029/2011WR011123.

Riahi, K., A. Grübler, and N. Nakicenovic, 2007: Scenarios of longterm socio-economic and environmental development under climate stabilization. Technol. Forecasting Soc. Change, 74, 887-935, https://doi.org/10.1016/j.techfore.2006.05.026.

— , and Coauthors, 2011: RCP-8.5-A scenario of comparatively high greenhouse gas emissions. Climatic Change, 109, 33, https://doi.org/10.1007/s10584-011-0149-y.

Sauchyn, D. J., J.-M. St-Jacques, and B. H. Luckman, 2015: Long-term reliability of the Athabasca River (Alberta, Canada) as the water source for oil sands mining. Proc. Natl. Acad. Sci. USA, 112, 12 621-12 626, https://doi.org/10.1073/pnas.1509726112.

Schindler, D. W., and W. F. Donahue, 2006: An impending water crisis in Canada's western prairie provinces. Proc. Natl. Acad. Sci. USA, 103, 7210-7216, https://doi.org/10.1073/pnas.0601568103.

Schnorbus, M. A., and A. J. Cannon, 2014: Statistical emulation of streamflow projections from a distributed hydrological model: Application to CMIP3 and CMIP5 climate projections for British Columbia, Canada. Water Resour. Res., 50, 8907-8926, https://doi.org/10.1002/2014WR015279.

Shrestha, R. R., M. A. Schnorbus, A. T. Werner, and A. J. Berland, 2012: Modelling spatial and temporal variability of hydrologic impacts of climate change in the Fraser River basin, British Columbia, Canada. Hydrol. Processes, 26, 1840-1860, https:// doi.org/10.1002/hyp.9283.

, D. L. Peters, and M. A. Schnorbus, 2014a: Evaluating the ability of a hydrologic model to replicate hydro-ecologically relevant indicators. Hydrol. Processes, 28, 4294-4310, https:// doi.org/10.1002/hyp.9997.

— M. A. Schnorbus, A. T. Werner, and F. W. Zwiers, 2014b: Evaluating hydroclimatic change signals from statistically and dynamically downscaled GCMs and hydrologic models. J. Hydrometeor., 15, 844-860, https://doi.org/10.1175/JHM-D-13-030.1.

Smith, S. J., and T. M. L. Wigley, 2006: Multi-gas forcing stabilization with Minicam. Energy J., 27, 373-391, https://www.jstor. org/stable/23297091.

Troy, T. J., E. F. Wood, and J. Sheffield, 2008: An efficient calibration method for continental-scale land surface modeling. Water Resour. Res., 44, W09411, https://doi.org/10.1029/2007WR006513.

Van Vuuren, D. P., and Coauthors, 2011: The representative concentration pathways: An overview. Climatic Change, 109, 5-31, https://doi.org/10.1007/s10584-011-0148-z.

Vincent, L. A., and D. Gullett, 1999: Canadian historical and homogeneous temperature datasets for climate change analyses. Int. J. Climatol., 19, 1375-1388, https://doi.org/10.1002/(SICI) 1097-0088(199910)19:12<1375::AID-JOC427>3.0.CO;2-0.

Wagener, T., K. van Werkhoven, P. Reed, and Y. Tang, 2009: Multiobjective sensitivity analysis to understand the information content in streamflow observations for distributed watershed modeling. Water Resour. Res., 45, W02501, https:// doi.org/10.1029/2008WR007347.

Wang, X., G. Huang, Q. Lin, and J. Liu, 2014: High-resolution probabilistic projections of temperature changes over Ontario, Canada. J. Climate, 27, 5259-5284, https://doi.org/ 10.1175/JCLI-D-13-00717.1.

_,- , and J. Liu, 2015a: Projected increases in near-surface air temperature over Ontario, Canada: A regional climate modeling approach. Climate Dyn., 45, 1381-1393, https:// doi.org/10.1007/s00382-014-2387-y.

,,$---Z$ Z. Li, and S. Zhao, 2015b: Ensemble projections of regional climatic changes over Ontario, Canada. J. Climate, 28, 7327-7346, https://doi.org/10.1175/JCLI-D-15-0185.1.

Wilby, R., S. P. Charles, E. Zorita, B. Timbal, P. Whetton, and L. O. Mearns, 2004: Guidelines for use of climate scenarios developed from statistical downscaling methods. IPCC Doc., 27 pp., http:// www.ipcc-data.org/guidelines/dgm_no2_v1_09_2004.pdf.

Wise, M., and Coauthors, 2009: Implications of limiting $\mathrm{CO}_{2}$ concentrations for land use and energy. Science, 324, 1183-1186, https://doi.org/10.1126/science.1168475.

Xiao, Z., S. Liang, J. Wang, P. Chen, X. Yin, L. Zhang, and J. Song, 2014: Use of general regression neural networks for generating the GLASS leaf area index product from time-series MODIS surface reflectance. IEEE Trans. Geosci. Remote Sens., 52, 209-223, https://doi.org/10.1109/TGRS.2013.2237780.

Zhou, X., G. Huang, B. W. Baetz, X. Wang, and G. Cheng, 2018a: PRECIS-projected increases in temperature and precipitation over Canada. Quart. J. Roy. Meteor. Soc., 144, 588-603, https:// doi.org/10.1002/qj.3231.

—, X X. Wang, and G. Cheng, 2018b: Dynamically-downscaled temperature and precipitation changes over Saskatchewan using the PRECIS model. Climate Dyn., 50, 1321-1334, https://doi.org/10.1007/s00382-017-3687-9.

,,--- , and $-2018 \mathrm{c}$ : Future changes in precipitation extremes over Canada: Driving factors and inherent mechanism. J. Geophys. Res. Atmos., 123, 5783-5803, https://doi.org/ 10.1029/2017JD027735.

— — _ — - Y. Fan, and G. Cheng, 2018d: A coupled dynamical-copula downscaling approach for temperature projections over the Canadian Prairies. Climate Dyn., 51, 2413-2431, https://doi.org/10.1007/s00382-017-4020-3. 